\title{
Relationship of Morphological Knowledge to Spelling \\ Silent Letter Endings in French \\ by
}

Ruth Mussar

A thesis submitted to the Faculty of Graduate and Postdoctoral Affairs in partial fulfillment of the requirements for the degree of

Master of Arts

in

Psychology

Carleton University

Ottawa, Ontario

(C) 2018, Ruth Mussar 


\begin{abstract}
This cross-sectional study of archival data from Francophone elementary students assessed morphological knowledge as a construct encompassing both implicit and explicit morphological skills, and the use of this construct in predicting children's morphogramme spelling. 123 children in grades 1 to 3 were assessed on four measures of morphological knowledge, which varied in terms of implicit and explicit morphological manipulations; morphogramme spelling; and their use of silent letter endings (SLEs) in novel situations. First graders struggled to complete explicit morphological tasks, while third graders reached ceiling level on implicit tasks, thus highlighting the importance of choosing appropriate measures for a target population. Factor analysis of the morphological measures confirmed a one factor solution for morphological knowledge. However, analyses failed to replicate prior research stating that morphological knowledge predicts morphogramme spelling. Finally, children rarely used SLEs; however, when they did, they displayed sensitivity to the appropriate phonological context for the letter used.
\end{abstract}




\section{Acknowledgements}

I am grateful my family for their support and encouragement during this tremulous time in my academic career, and particularly to my brother Cameron, for the enormous emotional support he provided me during these long, sleepless months. I would also like to express my great appreciation for my supervisor Monique Sénéchal for her valuable and constructive feedback during the planning, execution, and interpretation of these analyses. 
Table of Contents

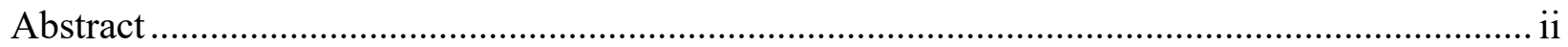

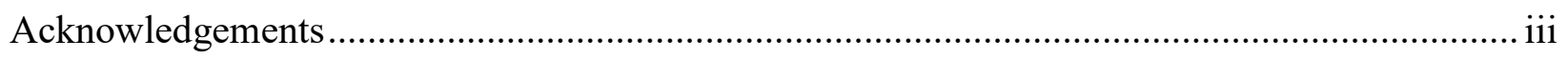

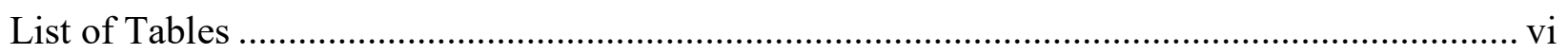

Relationship of Morphological Knowledge to Spelling ........................................................ 1

Silent Letter Endings in French ................................................................................... 1

Morphemes and Morphological Knowledge ................................................................... 3

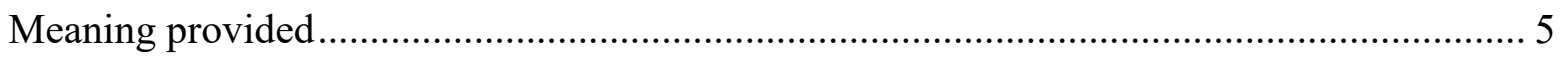

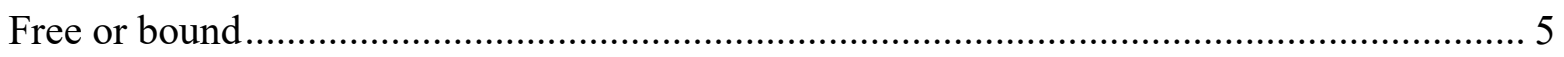



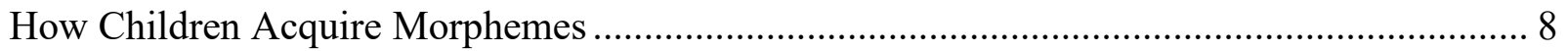

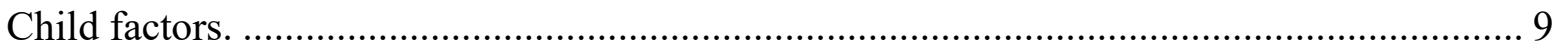

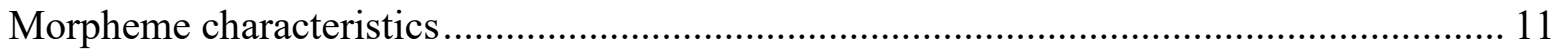

Measuring Morphological Knowledge.......................................................................... 12

French Orthography and Implications for Spelling ...................................................... 14

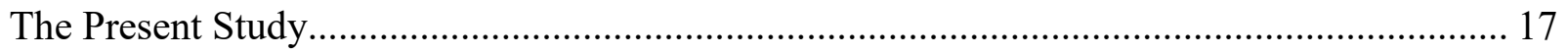

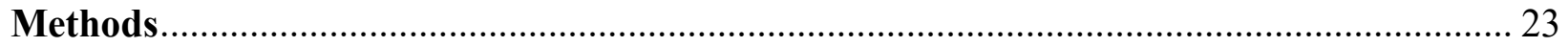

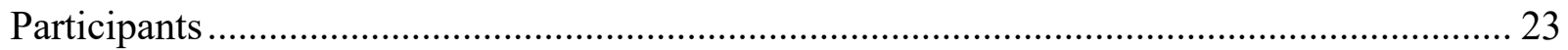

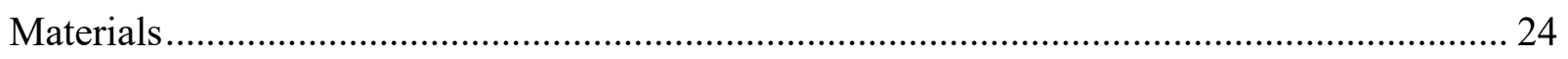

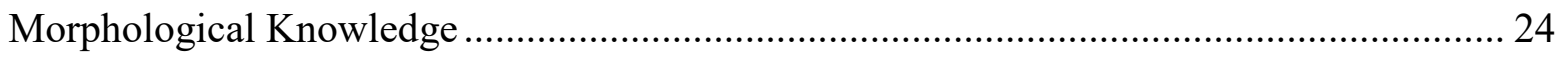

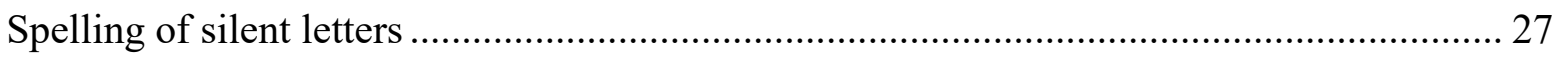

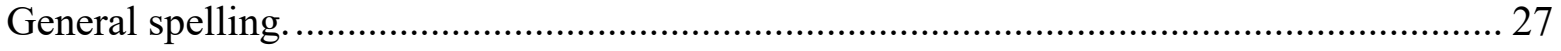

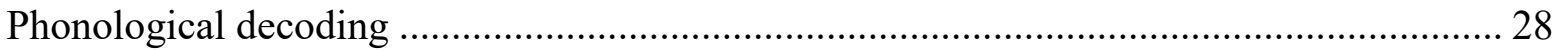

Over-extension of silent letters.................................................................................. 28

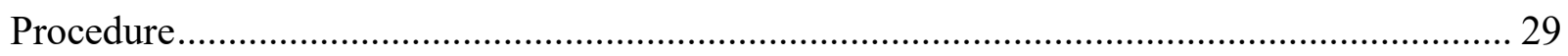

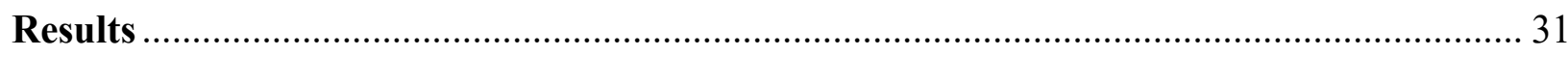

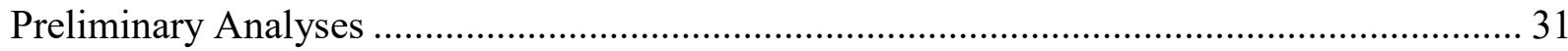

Utility of the Morpho-Phono Decomposition task ........................................................... 32

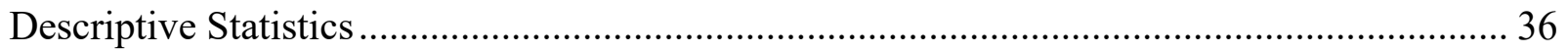

Factor Structure of Morphological Knowledge ............................................................... 40

Relationship Between Morphological Knowledge and Silent Letters ................................ 40

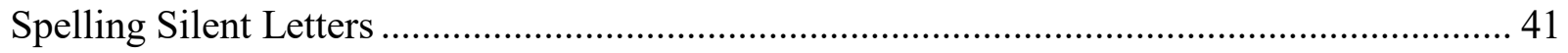




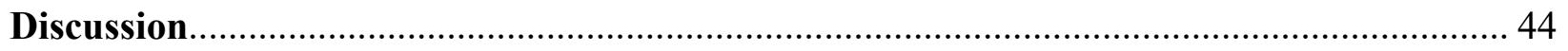

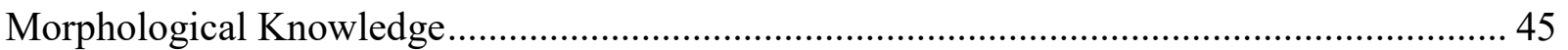

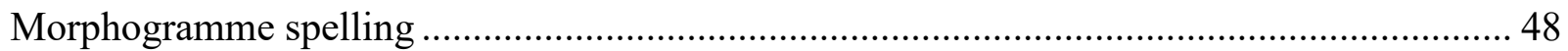

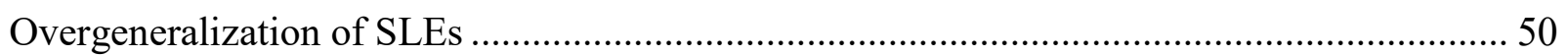

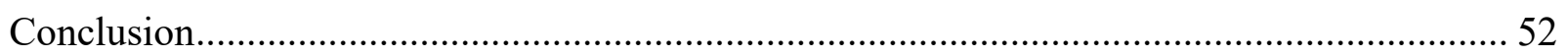

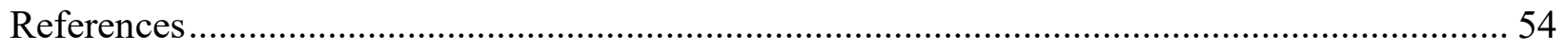

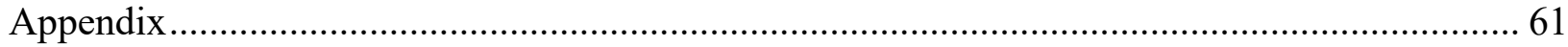


List of Tables

Table 1 Means (and Standard Deviations) of Children's Home Literacy Activities and Behaviours

Table 2 Proportions of Morphological Responses (and Standard Deviations) For Morpho-

Phono Decomposition Items by Affix 33

Table 3 Proportional Distribution of Answers to Morpho-Phono Decomposition Items by Grade and Affixation. 35

Table 4 Mean performance (and Standard Deviation) on Early Literacy Tasks as a Function of

Grade 37

Table 5 Pearson Correlations for All Measures...................................................................... 39

Table 6 Exploratory Factor Loadings and Communalities for Morphological Knowledge ....... 40

Table 7 Proportion of Children's SLEs by Phonological Rime. 42 


\section{Relationship of Morphological Knowledge to Spelling \\ Silent Letter Endings in French}

Teaching children to read and spell in French goes beyond simply associating letters with sounds. Though French contains only 26 letters (and 7 diacritics), French uses those letters to create hundreds of phoneme-grapheme (sound-symbol) pairs. Many children learn to decode text through the teaching of grapheme-phoneme correspondences - a method commonly referred to as phonics or the "sound out the word" method (Adams, 1990). However, this method is insufficient to teach children to spell, as children struggle to choose which of several possible graphemes accurately represents a target phoneme-for example, the sound /ẽ/ can be spelled 'en' or 'an'. Indeed, one estimate suggests that while $88 \%$ of French words can be consistently decoded based on phoneme-grapheme correspondences, only $21 \%$ can be consistently spelled by sound alone (Zeigler, Jacobs, \& Stone, 1996). Consequently, French is considered much easier to read than to spell (Abbott et al., 2016; Zeigler et al., 1996).

To make matters more difficult, some graphemes in French represent no sound at all. French abounds with silent letters, though the nature of its orthography is such that these letters usually occur at the end of words (Jaffré \& Fayol, 2006; Gingras \& Sénéchal, 2017). The Silex database of French orthography, a tool designed to facilitate the study of sound-to-spelling inconstancies (Gingras \& Sénéchal, 2017; adding to Peereman, Léte, \& Sprenger-Charolles, 2007, and New, Pallier, Brysbaert, \& Ferrand, 2004), estimates that 56\% of words present in children's reading material contain silent letter endings (SLEs). Furthermore, these endings often encode valuable grammatical or semantic information. For example, the words sang [blood] and sans [without] are both pronounced /sã/, but differ in both meaning and part of speech (being noun and preposition, respectively). Clearly, the information contained within SLEs contributes 
to a coherent narrative when writing, but by virtue of their silent nature, SLEs cannot be easily conveyed through speech. This, in turn, makes it difficult for children to learn these endings until they begin to read. Even then, the process is slow going — while the Québec provincial school curriculum expects children to be able to decode SLEs by the end of grade 2, children are not expected to master spelling them until grade 5 at the earliest (Québec Ministère de l'Éducation, 2009). Clearly, any strategy children can use to improve their SLE spelling provides a boon to their academic progress.

Research suggests that, given the morphological structure of French, that children's understanding of morphemes contributes to their early spelling (Sénéchal, Basque, \& LeClair, 2006; Desrochers, Monilitsis, Gaudreau, \& Georgiou, 2018). Morphemes are the smallest unit of meaning in a language (Carlisle, 2010; Kuo \& Anderson, 2006; Nagy, Carlisle, \& Goodwin, 2013). Consider the word chats [cats]. This word contains two morphemes: first, chat [cat], which refers to a small, furry quadruped commonly kept as a domestic pet, while the terminal $-S$ indicates that multiple cats being discussed. Children's understanding of morphology may provide an additional advantage to their spelling of SLEs, particularly if that SLE is a morphogramme. Morphogrammes are silent letters at the end the base form of a word which are pronounced in suffixed words of the same word family. For example, the $t$ in chant [to sing] is silent (the word is pronounced $/ \int \tilde{a} /$ ), but the $t$ is pronounced in the related word chanteur [singer]. By thinking about words in terms of their morphological relations, it is possible that children will be able to remember the presence of an SLE, and include it during spelling. One purpose of this thesis was to explore how morphological knowledge - the ability to understand and manipulate morphemes_-aids children in spelling morphogrammes. 
There has been some previous research exploring the relationship between morphology and morphogramme spelling, such as Sénéchal (2000) and Fejzo (2016). However, few studies have taken the time to thoroughly explore the construct of morphological knowledge, and how the measurement of this construct influences the interpretation children's performance. To begin, I provide a review of morphological knowledge, the factors which allow children to acquire morphological knowledge, and some of the common methods of assessing this construct. This is followed by a description of the French orthography and the acquisition of children's spelling skills, and finally a review of two prior studies which explored the effect of morphological knowledge on morphogramme spelling.

Throughout this paper, an effort was made to focus on the language of interest—French. However, the body of research on this language, though substantial, is by no means complete. In instances where research on a particular aspect of morphology has not been completed in French, the results of English studies have been reported. Both English and French have morphophonemic orthographies and use similar morphemic processes (e.g. grammatical suffixation; root consistency) and thus the results of morphological studies in one language are considered reasonably comparable to the other (Desrochers et al., 2018; Abbott et al., 2016). Morphemes and Morphological Knowledge

Morphological knowledge is a superordinate process that encompasses two skillsmorphological awareness and morphological processing (Bowers, Kirby, \& Deacon, 2010; Nagy et al., 2013). Morphological awareness refers to the ability to consciously recognize and manipulate morphemes (Kuo \& Anderson, 2006; Lam \& Chen, 2017). This includes being able to recognize and segment the subcomponents of words, identify the meaning of each component, and use these components to create novel words to fit a context. By contrast, morphological 
processing refers to the implicit ability to use morphemes to produce everyday language (Kruk \& Bergman, 2013; Nagy et al., 2013). For example, an English-learning three-year-old would, at an implicit level, understands that the $-s$ at the end of cats indicates plural, and could use that $-s$ to create the word shirts, even if they had never heard that word before. French-learning toddlers as young as 25 months recognise grammatical gender markers, and use them to direct attention to stimuli (van Heugten \& Shi, 2009). However, they do not yet have morphological awareness—if one were to ask a three-year-old why they added an $-s$ to the end a word, they would not be able to answer.

By grade 2, children have developed sufficient relational knowledge to see how some words share phonological, orthographic and semantic components beyond simple grammatical features. They are also capable of explicitly synthesizing or segmenting certain morphemes (Casalis \& Louis-Alexandre, 2000). Thus, by grade 2, children can recognize how subcomponents of a word have specific meanings, and that regardless of what word this subcomponent occurs in, its meaning remains constant, allowing them to decode novel words by analyzing their components. This is not to say that children are especially competent at these tasks - Casalis and Louis-Alexandre (2000) noted that children struggle to consistently and correctly manipulate morphemes on command. By grade 4, children are more competent at recognizing and using morphemes; however, they still struggle to define them, indicating that they do not possess a complete, explicit understanding of the function of these affixes (Carlisle, 2010) Thus, the development of morphological knowledge takes a very long time (Nagy et al., 2013; Nagy, Berninger, Abbott, Vaughan, \& Vermeulan, 2003).

There are several ways in which children can reflect upon and manipulate morphemes. The speed with which children acquire these abilities depends on the broader cognitive skills of 
the child and the difficulty of the morpheme or morphemic process. Before explaining how different morphemes are acquired throughout childhood, I will first classify the common types of morphemes based on their function, lexical status and clarity.

Meaning provided. When asked to consider the meaning of a morphologically complex word, many adults will first think of the base or root of the word. The root contains the "prime definition" of the word it contributes to (Hurry et al., 2005). Roots can be modified by the addition of an affix, which provides additional and unique meaning. Affixes that attach to the beginning of a word are called prefixes, while those that attach to the end are suffixes (Hurry et al., 2005). Though suffixes are more readily learned due to their sheer frequency (Kuczaj, 1979; St. Clair, Monaghan, \& Ramscar, 2009), children find it easier to manipulate prefixes, as prefixes do not blend with the syllable they attach to, nor do they alter the grammatical category of words (Desrochers et al., 2018; Beyersmann, Ziegler, \& Grainger, 2015)

Inflectional morphemes can be affixed to roots to indicate grammatical information such as verb tense, number, degree, gender or grammatical person (Sénéchal \& Kearnan, 2007; Goodwin \& Ahn, 2010; Carlisle, 2003)—notably, this occurs without changing the meaning of the root (Kuo \& Anderson, 2006). Derivational morphemes can be affixed to mark syntactic changes in the word, such as a shift in word class (e.g. rapid [fast] (adj.) $\rightarrow$ rapidement [quickly](adv.)) or meaning (e.g. faire [to do] $\rightarrow$ défaire [to undo]) (Carlisle, 2003; Sénéchal \& Kearnan, 2007). Finally, two words may be combined to form a new word in a process known as compounding (e.g. basketball) (Kuo \& Anderson, 2006). The bulk of this study will focus on derivational words.

Free or bound. Another way of classifying morphemes is by whether they are free or bound. Free morphemes can stand on their own as words, while bound morphemes have no 
lexical status and must be attached to other word components (Sénéchal \& Kearnan, 2007; Carlisle, 2003). Free morphemes can be root words, but not all roots are free-for example, the Greek root bio as in biology cannot subsist on its own. Affixes are also bound as they only provide meaning in the context of a root word.

Opacity. It has already been stated that, because of the inconsistency between sound-tospelling mappings in French, French as a language is considered opaque (Zeigler et al., 1996; Gingras \& Sénéchal, 2018). Morphology can also be classified as transparent or opaque, depending on whether the morphemic changes in the word also produce orthographic, phonological, or semantic shifts which obscure the relationship of the derived word to its root (Goodwin \& Ahn, 2010; Nagy \& Anderson, 1984). The suffix -sse as in jeunesse [youth] is very transparent as both the spelling and pronunciation of the root word jeune [young] are maintained, and both words share a similar meaning. The -eux in dangereux [dangerous] causes the 'er' to shift from /e/ in the root word danger [danger] to /ø/ in the suffixed word, although the spelling of the root word is still easily seen. However, the relation of précieux [precious] to its root prix [prize] is considerably opaque, as the composed word contains both phonological and orthographic changes. Children have more difficulty composing and decomposing opaque words than transparent ones (Carlisle, 2000), and often favour transparent affixes over opaque onesEnglish-learning children, for example, conjugate * producement ${ }^{1}$ instead of production (Tyler \& Nagy, 1989; Carlisle, 2000). The inability to see the relationship between a composed and root word is one source of composition difficulty; another is that transparent morphemes are more common in both English and French than opaque ones (Tyler \& Nagy, 1989; Nagy \& Anderson, 1984, Quémart \& Casalis, 2017), giving children more opportunities to become familiar with

\footnotetext{
${ }^{1}$ Asterisks denote ungrammatical words or phrases.
} 
transparent morphemes. Both English and French follow a principle of "root consistency", meaning that the spelling of the root word is maintained despite phonological shifts that may occur; for example, sign and signature and berger [shepherd] and bergerie [sheepfold] (Quémart \& Casalis, 2017; Lam \& Chen, 2017). Transparency strongly predicts when a child will acquire a particular morpheme, as orthographic and phonological shifts in derived words negatively impact children's ability to segment words into component morphemes (Carlisle, 2003; Nagy \& Anderson, 1984; Quémart \& Casalis, 2017).

A study by Nagy and Anderson (1984) analysed a random sample of 7260 English words from the Word Frequency Book (Carroll, Davies, \& Richman, 1971), and analyzed the graphic relatedness and degree of semantic relationships among words in the sample. Semantic relationships were considered transparent if the meaning of the target word could be determined from the meaning of its root and affix, with reasonably minimal aid from the surrounding literary context. Extrapolating their results to the broader realm of school vocabulary, Nagy and Anderson estimate that between grades 3 and 9 children will be exposed to over 45000 root words, and an additional 170000 derived forms. Furthermore, of these derived words, approximately 139000 of them possess sufficient transparency that a child could extrapolate the meaning of the word from a single exposure. Though these numbers may not reflect the quantity of root and derived forms learned by French elementary children, given the principle of root consistency, one may expect some proportion of French derivational words to be similarly transparent, especially considering that French orthography is relatively transparent when decoding phonemes from graphemes (Zeigler et al., 1996). That said, children must develop cognitive skills to allow them to recognize the relationships between roots and composed words 
to facilitate this decoding process. This process is further complicated by the complexity of the morpheme involved.

\section{How Children Acquire Morphemes}

Children begin to acquire morphemes as soon as they begin to recognize language. Morphological processing develops through experience and repeated exposure, as the mind forms implicit links between sounds and word meanings (Nagy et al., 2013; Carlisle, 2010). This eventually results in a mental lexicon that is morphologically organized (Casalis \& LouisAlexandre, 2000), allowing children as young as three years old to recognize and process words in terms of their morphological families, to segment highly productive prefixes and suffixes to decipher novel words, and to use these affixes to create new words (albeit with some difficulty) (Clark \& Hecht, 1982; Carlisle, 2010). At three years of age, children can produce twomorpheme words, and use inflectional morphemes to indicate number, verb tense and possession (Hurry et al., 2005). With time, children begin to recognize how common sounds in a word, such as a terminal -ment in French, indicate a common meaning-in this case, -ment indicates an adverb. Six-year-old children can implicitly use common derivational morphemes productively, and first graders can explicitly derive transparent, high-frequency derivational suffixes (Anglin, Miller, \& Wakefield, 1993; Carlisle \& Nomanbhoy, 1993). Importantly, with sufficient exposure to print, children acquire a new way of identifying common word components - they are able to recognize how some words contain common and specific visual elements. Children can then extend their capacities for morphemic analysis and decomposition to written text, allowing them to decode novel multimorphemic words; in turn, this may enable children to read more complex material, further increasing their exposure to novel words (Berninger et al., 2009; Goodwin \& 
Ahn, 2010). Even as they learn to associate oral vocabulary with written symbol sequences, they begin to recognize how certain smaller sequences provide unique meaning (Carlisle, 2010).

Berninger et al. (2009) assessed the growth of four types of derivational morphology in English-speaking children from grades 1 to 6 - suffixing roots to form derivations, decomposing derivatives into their roots, assessing semantic relations between words, and assessing syntactic appropriateness of suffixed words. Growth curve analysis determined that all skills showed the steepest growth in grades 1-3, with decomposition, semantic relations, and syntactic appropriateness leveling off in grade 4 . However, derivation through suffixing continued to show substantial growth up to grade 6 and potentially beyond. Berninger et al. suggest that the ability to transform words by adding suffixes allows children to read and spell low frequency, morphologically complex words with ease, allowing them to process a richer vocabulary. In turn, this allows for greater exposure to morphologically complex words, creating a sort of positive feedback loop for morphological growth. An alternate explanation is that the suffixation task is simply more effortful, as multiple suffixes could perform the appropriate root transformation.

To explain why morphological development takes so long, I will now discuss two sets of factors affecting how quickly morphemes become understood. First, the cognitive factors and skill sets of the child, and second, the qualities of the morphemes themselves.

Child factors. Three cognitive factors that affect children's ability to use morphology are their relational knowledge, syntactic knowledge, and distributional knowledge. Relational knowledge involves recognizing how roots and inflected, derived or compounded forms are related by common morphemes - for example, that heard comes from hear (Carlisle, 2010). It also governs recognizing when two similar looking or sounding words are not related-for example, beard does not come from bear. Syntactic knowledge refers to the awareness of how 
derivational affixes can affect the syntactic category of a word-for example, the nominalizer -er changes verbs such as to work into nouns such as worker. Finally, distributional knowledge involves recognizing the limitations on how certain roots and affixes can be combined. For example, the suffix -ness may attach to adjectives (e.g. playful $\rightarrow$ playfulness) but it cannot directly to nouns (e.g. * playness) (Tyler \& Nagy, 1989). From a series of tests assessing grade 4 to grade 8 students' morphological capacities, Tyler and Nagy (1989) proposed that syntactic knowledge develops after relational knowledge, as one must understand the relationship between a root and its derived form before one can assess the specific effect a suffix has on the part of speech of the root. Furthermore, distributional knowledge must develop after syntactic knowledge, as children would have to recognize the syntactic contribution of the suffix before understanding how its distribution is constrained.

Paralleling the growth of their cognitive skills is the acquisition of strategies children use to learn morphology. One of the earliest strategies learned is analogy, such as mice is to mouse as lice is to louse (Sénéchal \& Kearnan, 2007), as this strategy can be successfully used after relational knowledge develops. Recognizing that a root and derived word share some common meaning, children may then extend that knowledge to recognize that other roots and derived forms may be similarly related. Children six to seven years of age may do this implicitly using phonological rules - for example, if the plural of bug is pronounced /b^gz/, then the plural of wug must be pronounced /wıgz/ (Berko, 1958; Sénéchal \& Kearnan, 2007). By grade 5 (approximately 12 years of age), children's syntactic knowledge is sufficient to allow them to decode novel words through morphemic analysis — determining the meaning of a word by segmenting and analyzing its component morphemes (Baumann, Edwards, Font, Tereshinski, Kame'enui, \& Olejnik, 2002). However, consistent with Tyler and Nagy (1989), adolescents 
struggle markedly with this task, successfully defining only $60 \%$ of novel words (Baumann et al., 2002)

Morpheme characteristics. The frequency, productivity, and transparency of affixes strongly determine how easily they can be acquired. The frequency with which a morpheme occurs in written and spoken language seems an obvious predictor, as the more often a child is exposed to a morpheme, the more opportunities they will have to recognize that oral or written sequence and associate a meaning to it (Carlisle, 2003). Closely related to frequency is productivity. Productivity refers to how often and easily an affix can be used to manipulate the meaning of a word. For example, the French agentive suffix -eur is highly productive, attaching to numerous verbs to produce nouns with the meaning "one who performs the verb". Productive affixes have more opportunities to be used in language, and thus tend to be more frequent. Children may also need to use productive affixes more often, and so they will actively seek them out. Finally, the transparency of the morpheme, which refers to the intact pronunciation, spelling, or meaning of the root, predicts acquisition as morphemes whose meaning and effect on roots can be easily deduced are easier for children to encode (Tyler \& Nagy, 1989; Nagy \& Anderson, 1984).

Additionally, the function of the morpheme affects how quickly it is acquired. Inflections and the earliest (i.e. most frequent and regular) derivational morphemes develop rapidly through repeated exposure. Eventually, children begin to recognize these morphemes as entities in and of themselves, and form schemas which define the morphemes' meaning and syntax (Kuo \& Anderson, 2006). Next, they begin to overapply these schemas to any situation in which they desire to apply the morphemes' meaning. Sénéchal provides an example from her own lifewhen asked where a mouton [sheep] lives, her then 5-year-old daughter over-applied the suffix - 
erie to conjugate moutonnerie*, rather than bergerie [sheepfold] (Sénéchal \& Kearnan, 2007).

With experience, however, children learn to recognize irregular cases, and appropriately narrow their field of application (Kuo \& Anderson, 2006; Tyler \& Nagy, 1989). As such, children may acquire some derivational morphology before they begin to read. However, the bulk of derivational morphology is thought to emerge slowly, both implicitly in children's casual language and explicitly in their knowledge of how morphemes are used (Kuo \& Anderson, 2006, Casalis \& Louis-Alexandre, 2000). Derivations are more varied in nature, and consequently less frequent in regular speech - thus, it takes longer for children to achieve sufficient exposure to develop strong representations of these morphemes. Additionally, numerous derivational affixes may be applied to a single root, creating a complex word in terms of length, sound and meaning, obscuring the relationship of the root and derived form and preventing children from seeing the unique function of the morpheme (Sénéchal \& Kearnan, 2007).

\section{Measuring Morphological Knowledge}

Because morphological knowledge represents the culmination of implicit and explicit skill, it is important to consider how a particular instrument measures this construct. Furthermore, depending on the age of the child, some measures may provide a more accurate assessment of their capabilities than others. For example, implicit morphological processing is well-established by grade 1 , but grade 1 students do not perform highly explicit tasks except with great difficulty (Casalis \& Louis-Alexandre, 2000; Nagy et al., 2013; Kuo \& Anderson, 2006). The following are three tasks that represent the theoretical breadth of the implicit/explicit spectrum_relational judgement tasks, decomposition tasks, and analogy tasks.

In relational judgement tasks, children are asked to determine if two words-usually presented as root and derivative - are part of the same word family. For example, the words 
renard [fox] and renardeau [fox kit] are semantically related, but bague [ring] and baguette are not. While the absolute difficulty of the task may vary depending on the transparency of the (apparent) morphological relation, this task can ultimately be solved using implicit morphological processing. This task is considered appropriate for younger children, such as first graders, as it requires little in the way of working memory or cognitive effort. No morpheme manipulation is required on the part of the child - they need only make a gut decision as to whether the two words are semantically related (Colé, Royer, Leuwers and Casalis, 2004; Kirby et al., 2012). By contrast, decomposition requires children to successfully identify the root and affix of a word, and then isolate the root. This task relies on children's ability to explicitly manipulate morphemes, although implicit knowledge may also play a role, as children may be "primed" by hearing the root within the derived form.

Analogy is again more difficult. This task requires children to recognize a morphological relation in one word pair, and apply this relation to complete a second word pair; for example, haut [high]: hauteur [height]:: gros [large]:____ (grosseur [size]). Thus, this task requires both decomposition and production. Notably, studies generally find production tasks more difficult than decomposition tasks (Carlisle \& Nomanbhoy, 1993; Berninger et al., 2009). Furthermore, it is much harder to guess the correct answer to a production task (Deacon, Parilla, \& Kirby, 2008). Given the sophisticated level of reasoning necessary to complete this task, and the consequential strain on working memory, analogy tasks are often considered inappropriate for younger elementary children (Kirby et al., 2012). That said, some studies have successfully used analogy tasks with children in grade 2 (e.g. Desrochers et al., 2018).

In summary, the acquisition of morphological knowledge is highly dependent on the complexity of the morphemes and morphological processes being assessed. While children are 
quick to establish morphological processing, their capacity for explicit morphological manipulation takes longer to establish, and continues to grow beyond the elementary years. Consequently, when measuring morphological knowledge, one must choose a measurement instrument that can appropriately determine children's level of skill.

\section{French Orthography and Implications for Spelling}

Current models of orthographic learning suggest that children begin to learn to spell by first associating individual letters with sounds, and eventually refining their representations to whole word patterns (Ouellette, 2010; Sanchez, Mangan, \& Ecalle, 2012; Sénéchal et al., 2016). The practice of spelling provides its own positive feedback loop —as children attend to each letter of the target word and the sound associated with it, their mental representation of the word strengthens (Ouellette, 2010). However, when a grapheme is phonologically underspecified, children's representations of it may be "fuzzy" (Sénéchal et al., 2016). Consequently, when faced with a phonologically underspecified grapheme, such as a silent letter, children may not accurately represent what that letter is, if they represent it at all (Sénéchal et al., 2016; Gingras \& Sénéchal, 2018). This disrupts the positive feedback loop that fully specified graphemes benefit from, as children are less likely to attend to silent letters, and so do not strengthen their mental representations. In one study of students in grades 1 to 3 , approximately $65 \%$ of children's SLE spelling errors were the omission of the SLE (Sénéchal, Gingras, \& l'Heureux, 2016). Due to the principle of root consistency, however, French derivatives regularly maintain the same graphemes as their root word, and morphogrammes, though unpronounced (and underspecified) in the root, are salient in derived forms. Therefore, derivative words provide a way for children to encode otherwise silent morphogrammes - for example, children can spell the silent ' $t$ ' in chant [singing] by recalling its derivative chanteur [singer] (Fejzo 2016, Sénéchal et al., 2006; 
Sénéchal et al., 2016). Thus, even though morphogrammes are not morphemes in and of themselves, morphological knowledge may play a key role in their acquisition.

For opaque words, orthographic representation is the only way to recall SLEs, as children cannot rely on phonological strategies or morphological strategies to recall the ending. However, children in grade 4 use orthographic retrieval frequently and successfully to spell transparent and morphogramme words as well (Sénéchal et al., 2006). Critically, if a child does not know sufficient derivations of a morphogramme word (and thus, the child would consider that word opaque) the child may still successfully use orthographic retrieval to spell the morphogramme, creating the illusion that their morphological sensitivity is greater than it really is. Indeed, orthographic retrieval may be the strategy of choice even if the child does recall morphogramme derivations. Sénéchal (2000) notes that root words with large word families or high-frequency derivatives create orthographic redundancy, which eases the process of encoding these unusual grammatical features in memory. However, as the following studies show, children's morphological knowledge does account for additional variance in children morphogramme spelling, even after their general spelling (measured in terms of orthographic retrieval) was accounted for.

Sénéchal (2000) examined elementary school children's sensitivity to morphological information at the end of French words. Children's spelling of four word categories was assessed: transparent words, which had one-to-one phoneme-grapheme mappings (i.e. no silent letters throughout; lac (/lak/) [lake]); morphogramme words for whom a feminine version (or other derivation) revealed the silent letter ending (e.g. gentil (/Zẽti/) vs. gentille (/3ẽtij/) [gentle]); morphogramme words for whom an inflected or derived form revealed the silent letter, but which had no feminine form (e.g. début (/debu/) [beginning] vs. débutant (/debutã/)[beginner]), 
and opaque words, whose SLEs could not be revealed through affixation (e.g. prix [prize]).

Sénéchal hypothesized that morphogramme words would be easier to spell than opaque words because, even though both contain an SLE, the morphological relations between the morphogramme word and its extended word family may cue children to recall the silent letter. Morphological knowledge was assessed using an analogy task. Predictably, grade 4 children spelled more words correctly than grade 2 children, though they were far from ceiling level performance - grade 4 children spelled only $52 \%$ of morphogramme words and $68 \%$ of transparent words correctly. However, both grades found transparent words easier to spell than morphogramme words, which were in turn easier to spell than opaque words, supporting the hypothesis. When analyzing only words with silent consonant endings, morphogramme words with a feminine form were easier to spell than those without one, which were in turn easier to spell than opaque words. From this, Sénéchal concluded that children are sensitive to the morphological information at the end of French words. Finally, hierarchical regressions showed that morphological knowledge predicted morphogramme spelling after controlling for grade, general spelling, print exposure, vocabulary, and phoneme awareness. However, the effect was small; morphological knowledge explained only $2 \%$ of variance after control variables were accounted for. Nevertheless, this suggests that morphological knowledge is uniquely associated with morphogramme spelling, after controlling for numerous other early literacy skills.

Fejzo (2016) clarified the link between morphological knowledge, general levels of spelling, and morpheme-specific levels of spelling. French students in grades 3 and 4 were asked to spell 31 words containing either prefixes, bases with inconsistent graphemes, morphogrammes, or suffixes. Children's spelling accuracy was assessed at the whole word level and at the level of the individual morphemes within a word to compare the effects of 
morphological knowledge at the general and morpheme-specific level, respectively.

Morphological knowledge was also assessed using real and pseudoword derivation tasksunsurprisingly, children in grade 4 outperformed children in grade 3, although neither grade reached ceiling performance. Hierarchical regression revealed that morphological awareness predicted $4 \%$ of variance in morphogramme spelling and $9 \%$ of variance in suffix spelling after controlling for grade, word identification, non-verbal intelligence and phonological awareness. A subsequent hierarchical regression was done to assess whether morphological awareness predicted whole word spelling, and if so, if this effect was entirely due to morphological awareness' influence on morpheme spelling. While there was evidence that morphological awareness contributed to spelling complex words, once morpheme spelling was added to the model, the unique effect of morphological awareness disappeared. Thus, morphological awareness benefits children's spelling of French word endings, especially when these endings contain morphological information.

\section{The Present Study}

The present study of unanalyzed archival data aimed to improve upon our understanding of how Francophone children spell words with morphogrammes, and how morphological knowledge affects this process. This cross-sectional study assessed Francophone children in grades 1 to 3 . There were three major goals for this study. The first goal was to thoroughly assess the construct of morphological knowledge by analyzing the measures used to assess it in terms of the explicit morphological awareness needed to perform each of the measures. Having explored the nature of the construct, the second goal was to replicate the hierarchical regression performed by Sénéchal (2000), assessing how morphological knowledge predicts morphogramme spelling after controlling for other early literacy measures. The final goal of the study was to explore 
whether children use SLEs in novel orthographic situations, and if so, under what circumstances, thus providing a deeper understanding of how children adapt to a challenging aspect of French orthography.

Unlike Sénéchal, who assessed morphological awareness using a single task, this study assessed the broader construct of morphological knowledge using multiple measures. Specifically, three measures were used: first, a relational assessment task, where children were asked to judge if two words are semantically related; second, a decomposition task, wherein children were asked to identify the root of a derived word; third, a novel decomposition task, described below; and fourth, the analogy task used by Sénéchal (2000). This array of measures, which require varying levels of implicit and explicit morphological reasoning, was thought to be particularly suitable for acquiring a comprehensive estimate of elementary children's morphological knowledge. Thus, even if young children struggle to perform highly explicit morphological tasks, such as analogy, they might still display their morphological skill in implicit tasks, such as relational judgements. The present study examined children in grades 1 to 3, a slightly younger cohort than that examined by Sénéchal (2000) and Fejzo (2016). Of particular interest was not only how morphological knowledge differs across grade, but also how different grades performed on each of the morphological measures. Obviously, and in line with all prior research, children's morphological knowledge was expected to grow with experience, a construct approximated by grade. I hypothesized that task difficulty would increase as the amount of explicit morphological manipulation needed to solve said task increased. In other words, relatedness was hypothesized to be easier than decomposition, which was in turn hypothesized to be easier than analogy. While I did not expect the proposed rank order of difficulty to change across grades, an interaction was anticipated between grade and mean 
performance across tasks - it was anticipated that first graders, presumed to be the least experienced with explicit morphological manipulation, would show a larger decrease in mean performance as tasks required increased explicit manipulation; by contrast, third graders, presumed to be the most experienced with explicit manipulation, were expected to show a smaller decrease in mean performance across tasks. Before advancing to the next analysis, however, it would be prudent to first address a controversy with the use of decomposition tasks.

Although widely used (Tyler \& Nagy, 1989; Fejzo, 2016; Carlisle, 2000; Casalis \& Louis-Alexandre, 2000; Nagy et al., 2003), decomposition tasks have been criticized due to ambiguity as to whether children use morphological knowledge, phonological decoding or general vocabulary knowledge to complete them. Generally, the phonology of a root word is preserved to some degree within its derivative form - thus, we cannot know if a child successfully segments a word because they recognize the semantic relation between the root and derivative, or because they hear a "smaller word" within the derivative, or both. To address this, a new decomposition task was developed. Unlike traditional decomposition tasks, which note only if the child identified the semantic root of a word, this new task also tracked if the child identified a phonologically "smaller" word—for example, the word lire [read] in faiblir [weaken]. As an additional measure of phonological strategy use, some items of this task were unaffixed, meaning a smaller root could not be identified - for example, the word pardon [pardon]. If a child identified what they believed was a smaller word within this item-for example don (pronounced /dõ/) [donation] — then they must have used a phonological strategy to do so. By accounting for children's proclivity to use phonological strategies to decompose words, it may be possible to partial out this variability, creating a more accurate measure of children's morphological reasoning. The efficacy and validity of the new morphological- 
phonological decomposition task was assessed in two ways. First, through analysis of children's responses to items to confirm that the task did indeed capture phonological strategy use; and second, by examining its correlations to the traditional decomposition task, and how those correlations changed when the variance associated with children's use of phonological strategies was partialled out. A valid task would capture children's use of phonological strategies while also maintaining a reasonably strong, positive correlation to the other decomposition task, indicating that it is also a competent measure of morphological knowledge. While in general the morphological-phonological decomposition should be no more difficult than the traditional decomposition task, the items for which children must recognize that a semantically smaller word cannot be identified could prove more difficult and thus it was hypothesized that this task would be more difficult that the traditional decomposition task, though not so difficult as the analogy task.

As a final analysis of the morphological construct, a factor analysis of the four morphological measures was performed to assess whether they formed a single, unified construct, presumed to be morphological knowledge. It was possible that, given that each task might draw on some proportion of implicit or explicit skill, that a two-factor solution would present itself, presumably representing implicit morphological processing and explicit morphological awareness. However, while each task has been hypothesized to require varying amount of explicit cognitive effort, no task is wholly limited to the use of either implicit or explicit strategies. It is possible, if unlikely, that a child could expend greater cognitive effort to use morphological awareness to solve the relatedness task; similarly, a child could rely on instinct to conjugate words in the analogy task, even though this carries a high risk of error. In this case, a two-factor solution would be less likely, as no one measure would load cleanly onto 
either factor. Thus, it was hypothesized that a one factor solution would present itself. To the author's knowledge, this was the first factor analysis assessing the construct of morphological knowledge along the dimension of implicit and explicit morpheme manipulation.

At this point, having confirmed the structure of the morphological construct, the hierarchical regression performed by Sénéchal (2000) was performed to assess whether morphological knowledge accounted for children's spelling of SLEs, while controlling for their general levels of spelling. General experience (approximated by grade level), phonological decoding and general spelling were included as covariates in the model before adding morphological knowledge. If morphological knowledge explained a significant proportion of variance in the model after the addition other known predictors, it was considered a unique predictor of children's morphogramme spelling. Based on prior research, morphological knowledge was expected to provide a small but significant contribution to children's morphogramme spelling after other early literacy skills had been accounted for.

One final objective of this study was to note children's over-generalization of SLEs. Although the nature of spelling errors children make with morphogrammes is well documented (e.g. Sénéchal, 2000; Sénéchal et al, 2016; see also Bossé \& Pacton, 2006; Quémart \& Casalis, 2017) their general use of SLEs is not well understood. It is possible that, just as children go though a period of overgeneralizing morphemes, they may also go through a period of overgeneralizing morphogramme-like letter endings. A series of pseudowords, each with a rime that may elicit an SLE, were used to assess if children overgeneralized their use of SLEs. Pseudowords were preferred for this task so children's prior knowledge did not confound their spelling. If children did overgeneralize SLEs, it was expected that the letters $t$ and $e$ would be the most common, being the most and second most frequent SLEs, respectively (Gingras \& 
Sénéchal, 2017). However, children in grade 1 were not expected to overgeneralize SLEs, as it seems unlikely that they would have sufficient experience with written language to begin forming and over-using these sorts of schemas. 


\section{Methods}

\section{Participants.}

129 children between five and eight years old were recruited from four Francophone schools in Gatineau, Canada in 2007. Three children withdrew from the study partway through testing, and an additional three children were omitted due to substantially incomplete data- the final sample size was 123 . Children were recruited directly through the schools - a consent form was handed out by teachers to the children, and signed by parents at home. 46 children were in grade $1(M=6.3$ years, $S D=3.6$ months; 25 boys $), 51$ in grade $2(M=7.4$ years, $S D=4.1$ months; 33 boys), and 26 in grade 3 ( $M=8.5$ years, $S D=3.5$ months; 10 boys). All children spoke French, although many children spoke or were exposed to other languages in the home, including English (70.5\%); Arabic (7.7\%); Somali (3.1\%); Greek (1.6\%); Italian (1.6\%); German $(<1 \%)$; Russian $(<1 \%)$; Creole $(<1 \%)$; Spanish $(<1 \%)$; and Berbere $(<1 \%)$.

An estimate of children's exposure to literacy in the home was acquired by asking four questions about home literacy activities and behaviours. Two questions assessed children's enjoyment of reading and their frequency of reading in French, respectively. These questions were answered using four-point Likert scales ranging from Not at all/Never to Enormously/Very Often. The remaining two question assessed how often children were read to on a weekly basis, both in general and at bedtime specifically, with 9-point scales ranging from Never to More than 7 times a week. Four one-way ANOVAs assessing the mean differences between grades for each item were conducted, but none were significant $(F(2,117)=0.85, M S E=.43, p=.43$ for child reading enjoyment; $F(2,118)=0.87, M S E=.68, p=.42$ for child reading in French; $F(2,117)=$ $1.92, M S E=.5 .59, p=.15$ for reading at bedtime; $F(2,104)=0.62, M S E=6.01, p=.54$ for 
reading at other times). Thus, all grades were equivalent in their home literacy habits - the overall results are presented in Table 1.

Table 1

Means (and Standard Deviations) of Children's Home Literacy Activities and Behaviours

\begin{tabular}{lcccccc}
\hline & \multicolumn{2}{c}{ Grade 1 } & \multicolumn{2}{c}{ Grade 2 } & \multicolumn{2}{c}{ Grade 3 } \\
Item & $M$ & Range & $M$ & Range & $M$ & Range \\
\hline Child enjoys reading $^{\mathrm{a}}$ & $3.13(0.65)$ & $2-4$ & $3.08(0.57)$ & $2-4$ & $2.92(0.81)$ & $2-4$ \\
Child reads in French $^{\mathrm{b}}$ & $2.98(0.80)$ & $1-4$ & $3.02(0.77)$ & $1-4$ & $2.76(0.97)$ & $0-4$ \\
Reading at bedtime $^{\mathrm{c}}$ & $4.87(2.25)$ & $0-8$ & $4.43(2.53)$ & $0-8$ & $3.72(2.23)$ & $0-7$ \\
Reading at other times $^{\mathrm{c}}$ & $4.45(2.04)$ & $0-8$ & $3.85(2.61)$ & $0-8$ & $4.09(2.75)$ & $0-8$ \\
\hline
\end{tabular}

${ }^{\mathrm{a}} 0=$ not at all $; 1=\mathrm{a}$ little $; 2=$ a lot $; 3=$ enormously. ${ }^{\mathrm{b}} 0=$ never $; 1=$ rarely $; 2=$ often; $3=$ very

often. ${ }^{\mathrm{c}} 0=$ never $; 1=$ once $a$ week; $2=$ twice $a$ week $;. . ; 7=$ seven times $a$ week; $8=$ more than seven times a week.

\section{Materials}

Morphological Knowledge. Multiple morphological assessments were used to gain a comprehensive estimate of children's implicit and explicit morphological reasoning, and consequently achieve a well-rounded estimate of morphological knowledge. The four tasks assessed children's understanding of the relationship between roots and derivatives; their ability to deconstruct multimorphemic words; the difference between children's phonological and morphological decoding of words; and their ability to derive words through analogy.

Furthermore, three practice items with feedback were provided at the beginning of each task to familiarize the child with the task; no feedback was provided for test items.

Relatedness. This spoken test was adapted from Colé et al. (2004) and assessed children's ability to recognize whether two words were morphologically related. 20 pairs of words were used - these items are presented in the Appendix. The word pairs were all presented as root word: derived word, and all derivatives were suffixed. The suffixes (or pseudosuffixes) 
were phonologically transparent — this eased the difficulty of the task, as children find derivatives without phonological shifts easier to decompose than those with phonological shifts (Carlisle, 2003). Within each pair, one word was presented as a potential root and the other as a potential derivative. 10 pairs of words were morphologically related-for example, amour [love] and amoureux [amorous]; the remaining 10 pairs were orthographically and phonologically similar, but did not share a sematic root—for example, heure [hour] and heureux [happy]. The assistant administering the task told the child that they would hear two words that sounded similar, and that the child should say whether the words were part of the same "family" or not. Children received one point for each correct answer.

The internal consistency measure Cronbach's $\alpha$ was used to assess inter-reliability for all measures in this study. Generally, Cronbach's $\alpha$ is considered acceptable if it falls between .70 and .95-any lower suggests that the scale has substantial measurement error, and any higher suggests redundancy between items (Tavakol \& Dennick, 2011; Cortina, 1993). For this measure, inter-item reliability was acceptable (Cronbach's $\alpha=.69)$.

Decomposition. Children were orally presented 20 multimorphemic words (19 twomorpheme and one three-morpheme), and asked to find the "smaller word", or root word, within each item-for example, a smaller word within oreiller [pillow] is oreille [ear]. All items were suffixed derivatives. These items are presented in the Appendix. Children received one point for each word they successfully segmented into its root form. Although it was also desired to analyze children's phonological decompositions - that is, when children identified a smaller word via the sound of the derived word, and not through analyzing semantic relations - the archival nature of the data did not allow this. Inter-item reliability was good (Cronbach's $\alpha=$ $.83)$. 
Morphological-Phonological decomposition (Morpho-Phono decomposition). Children

were told that they would be presented with a series of words, some of which may contain a smaller word. The children were asked to identify if a smaller word existed, and if so, what it was. The 30 words were developed by Rey (Sénéchal \& Rey, 2007), 17 of which could be morphologically decomposed, with an approximately equal number of prefixed and suffixed words. The remaining words were unaffixed (i.e. had no smaller root within them). Regardless of affixation, all words contained a phonologically "smaller word" within. That is, children could identify the sounds of a smaller word within the larger word-for example, the ending of the word faiblir [weaken] sounds like the word lire [to read]. These items are presented in the Appendix. Unlike the previous test, where children were assessed solely on their ability to identify the morphological root, this test assessed whether children provided a morphological decomposition of a word (for example, identifying bond [jump] within rebond [rebound]) or a phonological decomposition (lire within faiblir). Children's answers were scored as either morphological, phonological, or other: a morphological answer indicated the child correctly identified the root of the target word, or correctly surmised that the target word had no smaller root; a phonological answer indicated the child used phonological decomposition to obtain their answer; an other answer indicated the child performed neither (for example, non-response, reporting only the first letter of the target word, or saying there was no root in a word that could be morphologically decomposed). Inter-item reliability of the scale as a whole was poor (Cronbach's $\alpha=.64$ ) with little difference between affixed (Cronbach's $\alpha=.50)$ and unaffixed items (Cronbach's $\alpha=.62$ ). Cronbach's $\alpha$ operates under the assumption of tau equivalence (Cortina, 1993) — that is, it assumes item standard deviations are equivalent — and it underestimates reliability when this assumption is violated. Item analysis revealed substantial 
differences between item standard deviations, with the lowest being $S D=0.25$ for the item droitier [right-handed person], and highest being $S D=.83$ for the item faiblir [weaken]. However, no appreciable increase in reliability was observed when removing individual items from the scale. Consequently, the scale was left whole for future analyses.

Analogy. This task was adapted from Sénéchal (2000) and designed to assess children’s ability to form derivatives from root words using analogy. Children were orally presented two words that shared a morphological relation, and were next provided the first item of a second pair. The children were then asked to deduce the missing item. For example, given the sequence "gris [grey (masc.)]: grise [grey (fem.)] :: blond [blond (masc.)]:___, the child would be expected to derive blonde [blond (fem.)]. The morphological transformation was always suffixation. Children received three practice items with feedback. There were 20 items, which are presented in the Appendix, and children were scored based on the number of items derived correctly. Inter-item reliability was good (Cronbach's $\alpha=.83$ ).

Spelling of silent letters. This written, classroom administered task assessed children's spelling of silent letter endings (SLE). Children were provided 30 sets of morphogramme words and asked to choose the correctly spelled word from three alternatives, all with an identical pronunciation. These alternatives included the word spelled with the correct SLE (e.g. chocolat [chocolate]); the word spelled with an incorrect letter ending (e.g. *chocolas); and the word with the silent letter omitted (e.g. * chocola). Children answered the items at their own pace, and received one point for each correctly identified word. Inter-item reliability was acceptable (Cronbach's $\alpha=.70)$.

General spelling. This classroom administered task provided a more general view of children's spelling abilities by assessing their orthographic representation. Children were 
presented with 30 pairs of words of with an identical pronunciation but alternate spellings-for example, jambe (leg) and *jembe. The items are presented in the Appendix. Children had to choose which of the two words was spelled correctly, and received one point for each correct answer. Inter-item reliability was acceptable (Cronbach's $\alpha=.72$ ).

Phonological decoding. This written, classroom administered task presented children with 30 pairs of non-words (e.g. fraze and traze), one of which was phonetically identical to a real word (e.g. phrase [sentence]). The items are presented in the Appendix. The children were asked to identify which non-word was pronounced like a real word. They received one point for each correct answer. Inter-item reliability was poor (Cronbach's $\alpha=.63$ ). However, there were only modest differences between item standard deviations - the lowest was $S D=0.12$ for the item harme, and highest was 0.50 for the items gam and eguiye. There were no appreciable increases in reliability when removing individual items from the scale. As with the morphophono decomposition task, it was decided to keep the scale whole for future analyses.

Over-extension of silent letters. From the Silex database (Gingras \& Sénéchal, 2017), the five most frequent silent letter endings overall are $e, t, d, s$, and $x$. However, the occurrence of any particular morphogramme is strongly conditional on the preceding phonological context. For example, many French words whose final syllable sounds as /aR/ end in a silent 'd', as in renard [fox] and canard [duck]. Furthermore, children in grades 1 to 3 are sensitive to this context (Sénéchal et al., 2016). 18 two-syllable pseudowords, each designed to elicit an SLE, were developed to assess whether children would over-extend their use of SLEs. To elicit a breadth of SLEs, six different phonological endings were used: three oral vowel endings (/o/, /i/, and /a/); two /R/ endings (/oR/ and /aR/); and one nasal vowel ending $(/ \tilde{a} /)$. The items are presented in the Appendix. 
This test was administered by classroom and presented as a spelling task. Children were provided a sheet of paper on which to write their answers. Given that only the spelling of the words' endings was of interest, it was decided to ease the difficulty of this test by providing the children with the first syllable of the word, and asking them to write the second syllable. The research assistant administering the task first explained that the children would be attempting to spell some "made up" words, and that children should try and provide an answer even if they are unsure of the proper spelling. The assistant dictated each pseudoword twice. To keep the assistant blind to the hypotheses of the study, children's answers were scored based on how closely their spelling matched the test items without the SLE, receiving one point for each word spelled correctly. However, the assistant was asked to note if children made spelling mistakes in the final letter position of the word; spelling mistakes unrelated to the final letter were ignored. An experimenter later totaled which of the five target SLEs, and how many, children used in their spelling. Inter-item reliability was good (Cronbach $\alpha=.86)$.

\section{Procedure}

The assessments were completed in school, during regular hours and at the teacher's convenience. All tasks were administered by a trained research assistant. After a brief period of time to acclimatize the students to the presence of the research assistant, testing began. Each child participated in a classroom wide session, during which the test for over-extension of silent letters, spelling of SLEs, general spelling and phonological decoding tasks were administered in this fixed order - the session in its entirety took 30-40 minutes. Children were tested in early winter, and there was concern that grade 1 children would not yet have enough experience with reading on their own to complete the aforementioned tasks. It was decided to exempt grade 1 children from these tasks to exclude potential confounds with their reading ability. Children from 
all grades each participated in a one-on-one session with the research assistant, during which the four morphological awareness assessments were administered in the following order: relatedness; decomposition; analogy; and Morpho-Phono decomposition. The one-on-one session took place in a quiet space at the school, such as an empty classroom or library. These sessions took 10-15 minutes. 


\section{Results}

\section{Preliminary Analyses}

Missing data analysis revealed that no variable was missing more than $5 \%$ of its data. As such, it was decided to assume the data were missing completely at random. Missing data were imputed using multiple hot-deck imputation (Crammer, Gill, Jackson, Murr, \& Armstrong, 2016). This imputation method assumes that values of a variable with missing data may be inferred by conditionally observing other participants who have a response to that variable. In other words, one participant's results on a measure may be assumed based on the results of another participant with similar characteristics. This method has been criticized as it potentially reduces variability in the data (Crammer \& Gill, 2013); however, when missing data are minimal, the variance lost using this "simple" imputation method is trivial. For each measure, potential information donors were identified by grade level, gender, and the remaining items in the measure. At this stage, the data were also checked for outliers within each grade. Minor outliers were present in several variables, including the traditional decomposition task, the morpho-phono decomposition task, the analogy task, and spelling SLEs. Most outliers represented a score that was unusually low for the sample. However, given that the deviation from the expected range of scores was fairly minimal, with outliers often being only one or two points below the lowest expected score, it was decided that they would not pose a significant threat to the distribution of the data, and they were left unchanged. Finally, given the high percentage of multilingual children in the sample, correlations were drawn between all measures and children's status as a French monolingual or multilingual student. All correlations were nonsignificant (largest correlation was $r=.14, p=.13$ ); thus, child language is not discussed further. 
Two items were removed from the Morpho-Phono decomposition task-one due to a potential confound in assessing children's answering strategies, and the other due to a morphological misassumption. The anticipated answer for the item jouet [toy] was that there was no root word present. However, the present tense of the verb jouer [to play] _ joue — in addition to being a valid phonological response, could be obtained by recognizing the semantic relation between "toy" and "playing". Furthermore, joue was by far the most common response to this item, accounting for more than $80 \%$ of all responses to this item - by contrast, the other valid phonological response est [is] was quite rare. Since children may have achieved this assumed to be phonological response through morphological reasoning, it was decided to remove this item from all analyses. The second omitted item was profil [profile], derived from the root fil [thread, wire]. Although both the prefix and root of this item are common in French, the semantic relation of the root to the derivative form has been obscured through time. Furthermore, this item could not be salvaged by reinterpreting it as a word with no derivative, as children could use a morphological strategy to obtain the word fil-namely, they could recognize and segment the prefix pro-.

\section{Utility of the Morpho-Phono Decomposition task}

The distribution of answers types within the morpho-phono decomposition task was analyzed with two goals in mind - first, to assess if the morpho-phono task did indeed capture children's use of phonological answers, and if so, how best to account for them in future analyses. The distribution of answer types within the Morpho-Phono Decomposition task was analyzed to assess whether children used phonological strategies when decomposing words as opposed to morphological strategies. Recall that morphological answers were those wherein the child successfully identified the root of a derived word, or correctly surmised that an unaffixed 
word had no internal root (i.e. it is, in and of itself, the root) and phonological answers were those wherein a child phonologically decomposed a word to identify the "smaller word". The pattern of morphological responses is presented in Table 2. For all prefixed and suffixed words, performance improved from grade 1 to grade $2(t(95)=2.77, p=.007$ for prefixed words; $t(95)$ $=3.64, p<.001$ for suffixed words) and improved marginally for unaffixed words $(t(95)=2.01$, $p=.047)$. Performance on prefixed words improved from grade 2 to grade $3(t(75)=2.82, p$ $=.006)$ but not for suffixed or unaffixed words $(t(95)=0.17, p=.86$ for suffixed and $t(95)=$ $0.35, p=.35$ for unaffixed words). Additionally, prefixed words were easier to decompose than suffixed words $(t(122)=3.86, p<.001)$, which were easier to answer than unaffixed words (for which the correct answer was "there is no root"; $t(122)=4.23, p<.001)$. Thus, the morphophono decomposition task appears to capture some of the known trends relating to children's morphological knowledge—namely, that children's morphological skill improves with age (and presumably, experience), and that children find prefixed words easier to decompose than suffixed words.

Table 2

Proportions of Morphological Responses (and Standard Deviations) For Morpho-Phono Decomposition Items by Affix

\begin{tabular}{llll}
\hline Affix Status & Grade 1 & Grade 2 & Grade 3 \\
\hline Prefixed & $0.45(.31)$ & $0.63(.30)$ & $0.80(.17)$ \\
Suffixed & $0.37(.21)$ & $0.54(.23)$ & $0.55(.19)$ \\
Unaffixed & $0.37(.25)$ & $0.39(.20)$ & $0.43(.22)$ \\
\hline
\end{tabular}

Table 3 presents the proportion of morphological, phonological, and other answers to the morpho-phono decomposition items. All values are significantly greater than zero, indicating that at all grades, children produced a significant number of morphological, phonological, and 
'other' responses. This provides some evidence that the morpho-phono decomposition task does capture children's use of phonological strategies when decomposing words. When exploring the relationships between answer types, however, a curious trend emerged. A negative correlation existed between children's morphological decompositions and phonological decompositions of affixed words, $r=-.53, p<.001$, and unaffixed words, $r=-.35, p<.001$. This indicates that children who use more morphological strategies to decompose words are less likely to use phonological strategies. However, children's morphological decompositions of affixed words were positively correlated with their use of phonological decompositions for unaffixed words, $r=$ $.52, p<.001$. This seems odd, as one would expect a child's use of phonological strategies to decrease as their use of morphological strategies increased. Additionally, children's use of morphological strategies for affixed words was not correlated with their morphological strategy use for unaffixed words, $r=.14, p=.12$. Thus, children seem to treat the unaffixed items differently than the affixed ones, in that how they adjust their decomposition strategies differs between affixed and unaffixed words. Conceptually, the unaffixed items should be the most difficult, as they require children to recognize that there is no smaller root word present. The mean differences among the morphological answers support this, as children scored lower on unaffixed words than they did on prefixed or suffixed words. I concluded that the unaffixed items may have been too difficult for this cohort of children, and thus the unaffixed items were dropped from the analyses. Consequently, the only remaining measure of children's use of phonological strategies was their phonological answers for the affixed words. This measure is surely an underestimate of children's phonological strategy use, since children may use a phonological strategy to decompose a word and, in doing so, identify the root — this would, however, be marked as a morphological answer. Nevertheless, as the number of phonological 
responses to affixed items was significantly above zero at all grades, it was decided to use this variable as an approximate of their phonological strategy use.

Table 3

Proportional Distribution of Answers to Morpho-Phono Decomposition Items by Grade and Affixation

\begin{tabular}{lcccccc}
\hline & \multicolumn{2}{c}{ Grade $1^{\text {a }}$} & \multicolumn{2}{c}{ Grade 2 } & \multicolumn{2}{c}{ Grade 3 } \\
Answer Type & $\begin{array}{c}\text { Affixed } \\
\text { Words }\end{array}$ & $\begin{array}{c}\text { Unaffixed } \\
\text { Words }\end{array}$ & $\begin{array}{c}\text { Affixed } \\
\text { Words }\end{array}$ & $\begin{array}{c}\text { Unaffixed } \\
\text { Words }\end{array}$ & $\begin{array}{c}\text { Affixed } \\
\text { Words }\end{array}$ & $\begin{array}{c}\text { Unaffixed } \\
\text { Words }\end{array}$ \\
\hline Morphological & 0.41 & 0.30 & 0.58 & 0.39 & 0.67 & 0.43 \\
Phonological & 0.17 & 0.33 & 0.12 & 0.43 & 0.09 & 0.41 \\
Other & 0.41 & 0.37 & 0.30 & 0.18 & 0.24 & 0.15 \\
\hline
\end{tabular}

Note. All values significantly different than zero, $t\left(45^{\mathrm{a}}, 50^{\mathrm{b}}, 25^{\mathrm{c}}\right)>3.41^{\mathrm{a}}, 3.39^{\mathrm{b}}, 3.60^{\mathrm{c}}, p<.0027$

As a final analysis of the morpho-phono decomposition task, correlations between the morpho-phono and traditional decomposition tasks were performed to see if the two decomposition tasks were sufficiently related. The morpho-phono and traditional decomposition task were moderately, positively correlated $(r=.49, p<.001)$, indicating that children who tend to score higher on one decomposition task score higher on the other as well; and yet, this correlation seems rather modest for two tasks that supposedly assess the same construct in nearly identical ways. Correlations were also drawn between the decomposition tasks and children's phonological answers in the morpho-phono task. Phonological answers were negatively correlated to children's scores in both the traditional decomposition task $(r=-.33, p<.001)$ and the morpho-phono task $(r=-.53, p<.001)$, indicating that the more phonological decompositions children make, the fewer morphological ones they make. Additionally, this provides evidence that children's performance in traditional decomposition tasks may be influenced by their propensity to use phonological strategies to decompose words. Given this, the morpho-phono decomposition task, being thus able to measure children's phonological strategy use, may be a 
more valid measure of children's morphological knowledge. Finally, partial correlations were drawn between the two decomposition tasks while controlling for phonological strategy use. The resulting correlation was a non-significant drop in the magnitude of the observed relationship ( $r$ $=.39, p<.001$; Fisher's $z=0.95, p=.34$ ). Thus, the relationship between the traditional and morpho-phono decomposition task is not completely mitigated by the effect of children's phonological strategy use, and children who score high on morphological decomposition in one task tend to score high on the other. From this, I concluded that the morpho-phono decomposition task is a valuable assessment of morphological knowledge, as it can measure both a child's tendency for morphological decomposition and phonological decomposition.

Furthermore, given the relatively modest correlation between the morpho-phono and traditional decomposition tasks, I believed there would be no significant collinearity issues in including both tasks in subsequent analyses.

\section{Descriptive Statistics}

Descriptive statistics for all measures are presented in Table 4. Performance on the morphological relatedness task was significantly better than the expected $50 \%$ chance of success for all grades (smallest was $t_{\text {Grade } 1}(45)=6.55, p<.001$ ), although children in grade 1 did not perform above chance for unrelated word pairs $(t(45)=-.41, p=.69)$. Mean performance on the decomposition (smallest was $t_{\text {Grade }}(45)=20.07, p<.001$ ), Morpho-Phono decomposition (smallest was $\left.t_{\text {Grade } 1}(45)=14.95, p<.001\right)$, and analogy tasks (smallest was $t_{\text {Grade } 1}=9.52, p<$ .001 ;) were all above zero. Finally, mean performance on spelling SLEs $\left(t_{\text {Grade } 2}=9.78, p<.001\right)$, phonological decoding $\left(t_{\text {Grade } 2}=16.74, p<.001\right)$ and general spelling $\left(t_{\text {Grade } 2}=10.85, p<.001\right)$ all exceeded their respective chance performance levels. That said, there is some evidence of a ceiling effect within phonological decoding for both grade 2 and 3, and a ceiling effect of general 
spelling in grade 3 . The mean for phonological decoding is neither skewed nor kurtotic for grade 2 students $($ skew $=0.35(S E=.33)$, kurtosis $=-.03(S E=.65))$, but they are less than ideal for grade 3 students $($ skew $=-0.88(S E=.46)$, kurtosis $=1.28(S E=.54))$. There is a slight left skew in general spelling in grade $3($ skew $=-0.16(S E=.46)$, kurtosis $=-0.52(S E=.89))$. Though these values do not represent a significant departure from the normal distribution, the lack of variance within these variables decreases their value to the planned hierarchical regression assessing the relationship between morphological knowledge and morphogramme spelling, as neither will covary strongly with the dependent variable.

Table 4

Mean performance (and Standard Deviation) on Early Literacy Tasks as a Function of Grade

\begin{tabular}{lrrr}
\hline & $\begin{array}{c}\text { Grade } 1 \\
\mathrm{n}=46\end{array}$ & \multicolumn{1}{c}{$\begin{array}{c}\text { Grade } 2 \\
\mathrm{n}=51\end{array}$} & \multicolumn{1}{c}{$\begin{array}{c}\text { Grade } 3 \\
\mathrm{n}=26\end{array}$} \\
\hline Morphological Knowledge & & & \\
$\quad$ Relatedness (20) & $12.57(2.66)$ & $14.98(2.60)$ & $16.19(2.59)$ \\
$\quad$ Related word pairs (10) & $7.74(1.87)$ & $8.06(1.21)$ & $8.30(1.22)$ \\
$\quad$ Unrelated word pairs (10) & $4.83(2.91)$ & $6.92(2.37)$ & $7.92(2.19)$ \\
Decomposition (20) & $11.72(3.96)$ & $15.00(2.40)$ & $17.35(1.62)$ \\
Morpho-Phono Decomposition (17) & $7.02(3.19)$ & $9.84(3.25)$ & $11.34(2.42)$ \\
$\quad$ Phonological Responses (17) & $2.96(1.94)$ & $2.02(1.58)$ & $1.54(1.24)$ \\
$\quad$ Analogy (20) & $2.94(2.09)$ & $6.37(2.73)$ & $7.96(2.78)$ \\
Spelling SLEs (30) & & $16.59(4.81)$ & $20.88(3.87)$ \\
Phonological Decoding (30) & & $23.43(3.60)$ & $23.46(3.20)$ \\
General spelling (30) & & $20.88(3.87)$ & $24.12(3.58)$ \\
\hline
\end{tabular}

Note. The maximum score is presented in parentheses following each measure.

A 3 (grade: 1 vs. 2 vs. 3) x 4 (tasks: relatedness vs. decomposition vs. morpho-phono decomposition vs. analogy) mixed design ANOVA, where grade was the between-subjects factor and task was the within-subjects factor, was conducted to confirm the expected trends in performance across grades and tasks — namely, that performance on all morphological measures improves with age, and that tasks which can be solved through implicit morphological 
processing are easier than those requiring explicit morphological awareness. The task order, from easiest to hardest, was hypothesized to be: relatedness; decomposition; morpho-phono decomposition; analogy. Given that the four morphological tasks do not have the same number of items, it was decided to convert their mean performance to proportions to allow fair comparison between their means. The analysis revealed a significant main effect of grade $(F$ $(2,120)=3824.54, M S E=14.55, p<.001)$ and task $(F(3,360)=375.51, M S E=5.65, p<.001)$. The interaction was not significant $(F(6,360)=1.23, M S E=5.65, p=.29)$. Tukey's pairwise comparisons indicated that, as expected, performance improved from grade 1 to $2(\Delta M=2.97$, $S E=.41, p<.001)$, and from grade 2 to $3(\Delta M=1.84, S E=.49, p<.001)$. Polynomial withinsubjects contrasts revealed significant linear and quadratic components — children's mean performance on tasks appears to be relatively equal between relatedness and traditional decomposition, and then decreases toward morpho-phono decomposition and again toward analogy. Four pairwise comparisons were performed to confirm which mean differences among tasks were significant. Confirming the visual trend, the relatedness and traditional decomposition tasks did not differ significantly $(\Delta M=.005, S E=.02, p=.73)$; morpho-phono decomposition was harder than the traditional decomposition $(\Delta M=.18, S E=.02, p<.001)$; and the analogy task was harder than the morpho-phono decomposition task $(\Delta M=.27, S E=.02, p<.001)$. In general, this provides support for the hypothesis that tasks that rely on explicit morphological awareness are more difficult than those that can be solved using implicit processing.

Correlations between all measures are presented in Table 5. The correlations between all morphological measures were significant, positive and moderate in strength, indicating that children who scored high on any one measure of morphological knowledge tended to score high on others as well. Children's phonological responses in the morpho-phono decomposition task 
generally had small but significant negative correlations with all measures, indicating that children who are more likely to use phonological decompositions perform worse on assessments of morphological knowledge, general spelling, and SLE spelling. However, phonological responses did not correlate with phonological decoding - in fact, no measure except for the relatedness task correlated significantly with phonological decoding. This is unusual, as prior research suggests phonological decoding is positively associated with many early literacy skills (Adams, 1990). In contrast to decoding, general spelling had moderate to strong positive correlations with all morphological tasks and with spelling SLEs, indicating that children's general capacity for spelling is strongly associated with their other early literacy skills. And finally, grade is moderately to strongly positively correlated with all measures except phonological responses (to which it is negatively correlate) and phonological decoding (to which it is uncorrelated), generally indicating that with age and experience, children's early literacy skills improve.

Table 5

Pearson Correlations for All Measures

\begin{tabular}{|c|c|c|c|c|c|c|c|c|}
\hline & 1 & 2 & 3 & 4 & 5 & 6 & 7 & 8 \\
\hline 1. Grade & - & & & & & & & \\
\hline 2. Relatedness & $.476^{* *}$ & - & & & & & & \\
\hline 3. Decomposition & $.589^{* *}$ & $.498^{* *}$ & - & & & & & \\
\hline $\begin{array}{l}\text { 4. Morpho-Phono } \\
\text { Decomposition }\end{array}$ & $.418^{* *}$ & $.583^{* *}$ & $.489^{* *}$ & - & & & & \\
\hline 5. Phonological Responses & $-.317^{* *}$ & $-.245^{* *}$ & $-.332^{* *}$ & $-.534^{* *}$ & - & & & \\
\hline 6. Analogy & $.613^{* *}$ & $.428^{* *}$ & $.509^{* *}$ & $.477^{* *}$ & $-.286^{* *}$ & - & & \\
\hline 7. General spelling & $.883^{* *}$ & $.506^{* *}$ & $.575^{* *}$ & $.485^{* *}$ & $-.305^{* *}$ & $.608^{* *}$ & - & \\
\hline 8. Phonological Decoding & .004 & $.238^{*}$ & .156 & .147 & -.021 & .198 & .049 & - \\
\hline 9. Spelling SLEs & $.427^{* *}$ & $.336^{* *}$ & $.431^{* *}$ & $347^{* *}$ & $-.237^{*}$ & .189 & $.696^{* *}$ & .149 \\
\hline
\end{tabular}




\section{Factor Structure of Morphological Knowledge}

The factor structure of the four morphological tasks was examined using an exploratory factor analysis. Although a one factor solution was expected, it was decided a priori to use promax rotation as, in the event of a multifactor model, this rotation allows the latent factors to correlate, a likely outcome as the hypothesized factors may still be facets of the same overarching construct, namely, morphological knowledge (Matsunaga, 2015). The classic "eigenvalues greater than one" criterion was used to determine the number of factors to retain (Matsunaga, 2015). The first eigenvalue was 2.49 , explaining $62 \%$ of variance, and was the only eigenvalue to exceed one. Thus, a one factor solution was considered appropriate. Factor loadings and communalities are presented in Table 6. All four measures have reasonably strong loadings ( $r=.65$ to .75$)$. The measures are well represented in this factor space, and no one measure accounts for a substantially larger amount of variance. This confirms the hypothesis that, despite the measures assessing different proportions of implicit or explicit morphological reasoning, they all assess a unified construct.

Table 6

Exploratory Factor Loadings and Communalities for Morphological Knowledge

\begin{tabular}{lcc}
\hline & Factor Loadings & Communalities \\
\hline Relatedness & .730 & .533 \\
Decomposition & .693 & .480 \\
Morpho-Phono Decomposition & .752 & .566 \\
Analogy & .645 & .416 \\
\hline
\end{tabular}

\section{Relationship Between Morphological Knowledge and Silent Letters}

Given that all morphological measures load onto a single construct, it was decided to use the factor loadings from the EFA as an aggregate measure of morphological knowledge. This, in 
turn, was used in a hierarchical linear regression to determine if morphological knowledge predicts children's morphogramme spelling after general spelling is accounted for. The control variables — general spelling, grade, and phonological responses to the morpho-phono task—were entered in a single block, using forward selection. Variables in the equation were entered in descending order of the strength of their correlations to spelling SLEs (Howell, 2008). Previous research suggests that phonological decoding predicts children's spelling-however, the present measure of phonological decoding did not correlate with most other measures, SLE spelling included, and consequently it was not expected to account for a significant proportion of variance in spelling SLEs. Thus, phonological decoding was omitted from the model. The final model was significant $\left(R^{2}{ }_{a d j}=.50, F(2,74)=39.25, p<.001\right)$, and contained general spelling $(\beta$ $=.62, p<.001)$ and grade $(\beta=.19, p=.03)$ - phonological response was not a significant predictor $(\beta=-0.14, p=.10)$, though morphological knowledge trended towards significance $(\beta$ $=0.17, p=.06$ ). If forced into the model, morphological knowledge explains $2.3 \%$ of observed variance in spelling SLEs. Thus, morphological knowledge does not appear to account for significant variation in children's spelling of SLEs once their general spelling has been accounted for.

\section{Spelling Silent Letters}

To assess if children overgeneralize their use of SLEs, their proportional use of SLEs following pseudowords with various rimes was tabulated — the results are presented in Table 7. Overall, children rarely use SLEs when spelling unfamiliar words although their proportion of usage does increase slightly with age $-92 \%$ of grade 1 children's answers were an omission of any SLE, while only $79 \%$ of grade 3 children's answers were omissions. Furthermore, there was some variability based on the phonological rime-while between $95 \%$ to $99 \%$ of children's 
responses following the rime /o/ were omissions, only $59 \%$ to $83 \%$ of responses following /aR/ were. When SLEs are used, the letter $e$ is most common across all ages and phonological contexts, though particularly following the oral vowel /i/ and words ending in an /R/. Strikingly, children in grade 2 and 3 seem to have some sensitivity to the letter ' $d$ ' in specific contexts. Specifically, they use a terminal $d$ following /aR/, as in fenar, or /oR/, as in travor. Furthermore, within /aR/ words, there exists a proportional decrease in the use of $e$ over $d$ as children enter grade 3 , as a $\chi^{2}$ test of homogeneity found that the distribution of SLE responses within this rime was not equivalent across grades $\left(\chi^{2}(4)=39.4, p<.001\right)$. This provides some evidence that, by this age, children restrict the context in which they use silent letter endings to the most appropriate letter. However, children's use of the silent letters $t, s$ and $x$ is almost non-existent.

Table 7

Proportion of Children's SLEs by Phonological Rime

\begin{tabular}{cccccccc}
\hline Rime & Grade & $\mathrm{e}$ & $\mathrm{t}$ & $\mathrm{d}$ & $\mathrm{s}$ & $\mathrm{x}$ & Omission \\
\hline /a/ & 1 & 0.01 & - & - & - & - & 0.99 \\
& 2 & 0.03 & 0.01 & - & - & - & 0.96 \\
& 3 & 0.03 & - & 0.01 & - & 0.01 & 0.95 \\
/i/ & 1 & 0.04 & - & - & 0.01 & - & 0.96 \\
& 2 & 0.10 & - & - & - & - & 0.90 \\
& 3 & 0.24 & 0.01 & - & - & - & 0.74 \\
/o/ & 1 & 0.01 & - & - & - & - & 0.99 \\
& 2 & 0.01 & - & - & - & - & 0.99 \\
& 3 & 0.03 & - & 0.01 & 0.01 & - & 0.95 \\
/oR/ & 1 & 0.21 & - & - & - & - & 0.79 \\
& 2 & 0.30 & - & 0.05 & - & - & 0.65 \\
& 3 & 0.18 & 0.05 & 0.13 & - & 0.01 & 0.63 \\
& 1 & 0.17 & - & - & - & - & 0.83 \\
/aR/ & 2 & 0.16 & 0.01 & 0.10 & - & - & 0.72 \\
& 3 & 0.06 & 0.06 & 0.28 & - & - & 0.59 \\
& 1 & 0.04 & - & - & - & - & 0.96 \\
& 2 & 0.05 & 0.02 & - & 0.01 & - & 0.93 \\
& 3 & 0.03 & 0.04 & 0.03 & - & 0.01 & 0.90
\end{tabular}




\begin{tabular}{cccccccc}
\hline Average & 1 & 0.08 & - & - & - & - & 0.92 \\
& 2 & 0.11 & 0.01 & 0.03 & - & - & 0.86 \\
& 3 & 0.09 & 0.03 & 0.08 & - & 0.01 & 0.79 \\
\hline
\end{tabular}




\section{Discussion}

The goal of the present study was to replicate and expand upon research assessing whether morphological knowledge - the superordinate process that governs both the tacit use of morphemes in everyday language and the conscious manipulation of morphemes - is associated with children's spelling of morphogrammes — silent letter endings that are pronounced in derived members of a word family. Presumably, if children think of words in terms of their morphological relations, they may be able to infer the presence of an SLE within a root word by recalling their presence in the broader word family. To begin, the construct of morphological knowledge was examined in detail, with especial attention to how it encompasses both implicit and explicit morphological skills. Four measures of morphological knowledge were chosen for this study, each requiring successively more explicit morpheme manipulation on the part of the child. I hypothesized that tasks which require greater explicit effort, such as analogy, would be more difficult than those that could be solved through implicit means alone, such as relatedness. In general, the results of the analyses supported this hypothesis-relatedness and traditional decomposition were the easiest tasks, and analogy was the hardest. Furthermore, a potential confound in traditional decomposition tasks was identified, and a novel decomposition task — the morpho-phono task — was proposed as a useful alternative to traditional decomposition tasks. Additionally, the factor structure of morphological knowledge was assessed, providing evidence that, despite the fact that the measures used to assess it varied along the implicit/explicit cognitive spectrum, they all assess a single, unified construct. Having confirmed the structure of the morphological construct, its benefit to morphogramme spelling was assessed. Contrary to expectations, morphological knowledge did not explain a significant amount of variance in children's morphogramme spelling once control variables were accounted for. Finally, children's 
overgeneralization of SLEs was described, to provide a basis for further study into if and when Francophone children develop and overapply schema dictating the use of SLEs in novel situations.

\section{Morphological Knowledge}

Though there is a dearth of studies into how children manipulate morphemes, researchers are often lax in their definition of the construct of interest (Kirby et al., 2012; Bowers et al., 2010). This presents a major issue in the assessment of young elementary students, particularly those in Grade 1, because their capacity for explicit morphological manipulation is unstable (Casalis \& Louis-Alexandre, 2000; Nagy et al., 2013; Kuo \& Anderson, 2006). Furthermore, though some studies have acknowledged the importance of choosing morphological measurements (e.g. Bowers et al., 2010; Desrochers et al., 2018), few have taken the time to assess how different measures affect the nature of the resulting construct. For example, in recognition of the shift between implicit and explicit morphological manipulation that occurs around grade 1, Casalis \& Louis-Alexandre (2000) developed a substantial array of measures to assess children's implicit and explicit morphological skills in kindergarten through grade 2however, while they assessed children's performance across grades within the implicit and explicit measures, they did not compare performance between implicit and explicit measures. Thus, it could not be ascertained whether the use of both implicit and explicit tasks captured a broader view of children's morphological knowledge. In the present study, four tasks were chosen — relatedness, traditional decomposition, morpho-phono decomposition, and analogyeach believed to require progressively more explicit morphological manipulation. In general, tasks believed to require more explicit cognitive effort were more difficult—analogy was 
significantly harder than morpho-phono decomposition, which was in turn more difficult that traditional decomposition and relatedness.

Although mean performance on traditional decomposition and relatedness did not differ, they cannot be considered equivalent in difficulty due to differences in the interpretation of their means. Mean performance on the relatedness task represents the average of 20 yes/no questions, while the mean of traditional decomposition represents the average of 20 open-ended questions. While admittedly the potential answer pool for each open-ended question is not large (children are expected to reply with words or sounds within the presented item), the answer pool for each item may still be larger than the pool of two used in the relatedness task. Thus, although the means of relatedness and decomposition are equal, it takes more effort for children to score as high on decomposition as relatedness as they must choose from a greater number of potential answers, and thus decomposition may still be considered the more complex task.

An interaction effect between grade and task was anticipated-first graders were expected to show a relatively steeper decrease in mean performance relative to third graders, reflecting their lack of experience with explicit morphological manipulation. However, this interaction did not manifest. Indeed, from the steep decrease in performance between the traditional decomposition, morpho-phono decomposition, and analogy tasks, it may be interpreted that children of all grades struggled to perform when tasks required explicit morphological manipulation. In fact, although Desrochers et al. (2018) report that analogy tasks are appropriate for children beginning grade 2, grade 1 students in this study answered on average just two of 20 questions correctly. However, children in grade 3 performed near ceiling level in the relatedness and traditional decomposition tasks. Thus, tasks requiring marked explicit manipulation appear to be almost too difficult for first graders, but tasks which require very little 
appear too easy for third graders. This highlights the importance of defining the target construct, and the measures used to assess it, in terms of the population of interest — by choosing a set of measures that reflected the breadth of implicit and explicit processes involved in morphological knowledge, it possible to gain a detailed view of morphological knowledge across a varied population. That said, and in spite of the range of difficulties presented by these measures, they all loaded on a single factor. To this researcher's knowledge, this is the first time a factor analysis has been done to assess the structure of morphological awareness in a child population. Thus, this study provides evidence that morphological knowledge is the culmination of both implicit morphological processing and explicit morphological awareness.

Theoretical concerns have been voiced that traditional decomposition tasks can be solved with phonological strategies rather than morphological ones, artificially inflating children's apparent morphological skill. The morpho-phono decomposition task was developed to test this theory by first using items that may elicit phonological decompositions, and noting when children use an alternate decomposition strategy. Correlations revealed that scores on a traditional decomposition task correlated with the use of phonological decomposition strategies in the morpho-phono task, supporting the theoretical concerns. The novel decomposition task captures these phonological responses and is also a decent measure of morphological knowledge as it correlates moderately and positively with other measures of the construct.

The unaffixed items appeared to be too difficult for children to reliably answer - in fact, as children get better at morphologically decomposing affixed words, they became more likely to use phonological strategies to decompose unaffixed words. This may have been a response bias in that children may be reluctant to say "there is no smaller word" when a phonological strategy could be used to identify one. One avenue for future research would be to explore differences in 
the cognitive effort required for children to recognize that a word cannot be decomposed. However, an alternate interpretation may be that children infer the presence of a cranberry morpheme within these words. A cranberry morpheme is a bound morpheme possessing no intrinsic meaning and only present in a handful of words in a lexicon, whose presence serves to distinguish one word from another (Anderson, 1990) - for example, the cran- in cranberry does not occur outside this word in English, but distinguishes this berry from others, such as blueberries or strawberries. Children may have presumed the phonological pseudoroots of the unaffixed items to be true root words, and the remaining phonological components to be cranberry morphemes. For example, when considering the unaffixed item café (pronounced /kafe/) [coffee], children may consider the phonological pseudoroot fée [fairy] to be a true root, and the remaining $c a$ - to be a prefixed cranberry morpheme. Under this interpretation, the positive correlation between children's morphological decomposition of affixed words and their phonological decomposition of unaffixed words makes sense as, when faced with a word they have never decomposed before, children who excel at identifying true roots and affixes may be predisposed to interpret these words in a morphological way. Thus, the unaffixed items of the morpho-phono decomposition task may still have measured children's morphological strategy use, albeit in an unexpected way.

\section{Morphogramme spelling}

Having explored the structure of the morphological knowledge construct, the next goal of the present study was to replicate the hierarchical regression performed by Sénéchal (2000), assessing whether morphological knowledge predicts morphogramme spelling after other early literacy measures are accounted for. However, and in contrast to prior research, once children's general level of spelling was accounted for, their morphological knowledge did not explain a 
significant amount of variance in morphogramme spelling, though it did trend toward significance. Notably, the amount of explained variance in morphogramme spelling $-2.3 \%-$ was comparable to the $2 \%$ found by Sénéchal (2000) and 4\% found by Fejzo (2016). Given this, and the consideration with which the morphological construct was developed, the failure of morphological knowledge to explain a significant proportion of variance in morphogramme spelling may not be evidence that the proposed relationship doesn't exist. Instead, it may be the result of the strong correlation between general spelling and all other measures rendering other predictors insignificant. Prior research has placed the correlation between children's general spelling and morphogramme spelling at $r=.47$ to .60 (Sénéchal, 2000; Sénéchal et al, 2006)—in the present study, the correlation approached $r=.70$. In the present study, two separate measures with unique items were used to assess general and SLE spelling; however, both tasks took the form of a multiple-choice assessment in which children chose the correctly spelled word from a misspelled alternative. Thus, both tasks may be considered a measure of orthographic representation in that they required sight recognition of a specific orthography, which would explain the large correlation between SLE and general spelling. There may be some argument that the tasks are unequal in difficulty, as grade 3 students reached ceiling performance in general spelling but not morphogramme spelling, However, the morphogramme spelling task required children to choose from three possible responses, as opposed to two in the general spelling task. Therefore, the difference in difficulty may be the result of cognitive strain when choosing from a larger number of alternatives.

One overarching limitation of this study was the decision not to measure grade 1 students' phonological decoding, general spelling or morphogramme spelling. This decision arose from concern that children in grade 1 would not have enough experience with independent 
reading to answer the items. However, the items for these three literacy measures were chosen with grade 1 students in mind, such that the frequency and complexity of the words would be within the skill range of these children. Not only does the omission of the grade 1 students limit the generalizability of the results to a narrower age range, but because the literacy measures were designed with a younger cohort in mind, they may in fact have been too simple for the grade 2 and 3 students. This may explain the ceiling effects noted in the grade 2 and 3 populations for phonological decoding, and in the grade 3 for general spelling, and also explain why, despite prior literature citing phonological decoding as a significant predictor of children's spelling (Singson, Mahony, \& Mann, 2000; Abbott et al., 2016; Fejzo, 2016), this measure did not correlate significantly with any measure (except morphological relatedness). These skills undergo tremendous growth during early childhood (Adams, 1990; Casalis \& Louis-Alexandre, 2000; Abbott et al., 2016), and thus future research should take caution against using a "one size fits all" measure, as it may not accurately reflect the variance in skill level across young, growing populations.

\section{Overgeneralization of SLEs}

Silent letter endings present great difficulty to children's spelling. First graders succeed in only $14 \%$ to $34 \%$ of instances when spelling non-morphogramme words with SLEs; this increases to $55 \%$ to $84 \%$ in grade 3 (Sénéchal et al., 2016; Gingras \& Sénéchal, 2018). The most common type of spelling error is omission of the SLE, representing $52 \%$ to $66 \%$ of errors (Sénéchal, 2000; Sénéchal et al., 2016). In the present study, children of all grades rarely used SLEs when spelling novel words. While first graders, being novice readers, were not expected to have the experience necessary to understand the important of SLEs in French orthography, it was expected that older children would use more SLEs when writing pseudowords, given that they 
have more established representations of these letters (Gingras \& Sénéchal, 2018). However, there was a small trend for older children to use more SLEs than younger ones. It is possible that, given the long period it takes for children to master spelling SLEs (Québec Ministère de 1‘Éducation, 2009; Gingras \& Sénéchal, 2018), the expected overgeneralization does not occur until a later age.

The five most common SLEs in French are $t, e, s, x$, and $d$ (Gingras \& Sénéchal, 2017) In the present study, the most common letter used by children was $e$. Though it is possible that sheer frequency influences $e$ 's popularity, the letter $t$, the most common SLE overall, was almost never used. Furthermore, the letter $d$ is the least frequent SLE among the five represented in this study-however, it was the second most used by this cohort of children. Thus, frequency of the SLE in French text does not seem to drive children's acquisition of the SLE. The use of $e$ could tentatively be explained through its involvement with the French process of feminization. All nouns in French possess a grammatical gender, and many have male and female variants which change their orthography and phonology (Jaffré \& Fayol, 2006). A terminal letter $e$ often denotes a feminine form of a word (e.g. bavard (masc.) vs. bavarde (fem.) [chatterbox]). This is one of the earliest inflectional processes taught in Québec schools — children are expected to identify noun gender by grade 2 , and to reliably switch between masculine and feminine variants by grade 4 (Québec Ministère de 1'Éducation, 2009). It is possible, then, that the association of $e$ to this common and explicitly taught inflectional process makes it particularly salient — thus, $e$ may become a "go to" SLE for novel words.

The letter $d$ is not associated with a common grammatical process, and yet children showed not only a propensity to use it, but also sensitivity to its appropriate phonological context. The SLE $d$, although not particularly common overall, occurs fairly regularly in words 
ending with /R/ (Gingras \& Sénéchal, 2017). In the present study, children used the SLE $d$ almost exclusively following the rimes /aR/ and /oR/. Anecdotal evidence even suggests a grade effect. In grade $1,17 \%$ of SLE responses to the /aR/ rime were $e$, and $0 \%$ were $d$-by grade 3 , only $6 \%$ of SLE responses were $e$, while $28 \%$ were $d$. Perhaps the letter $d$ is easier to acquire because it has a very narrow phonological domain, to which it is strongly associated. Children displayed sensitivity to the phonological context of $e$ as well, using it in phonological contexts appropriate for the SLE (e.g. /i/, /oR/, /aR/) and omitting it from contexts where it occurs infrequently (e.g.

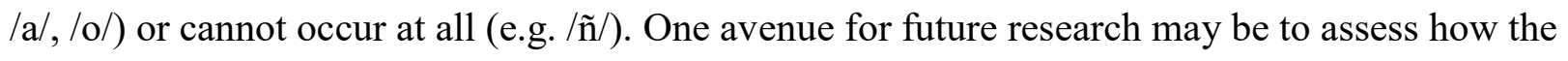
combination of frequency and phonological rime specificity affect children's acquisition or overgeneralization of SLEs.

\section{Conclusion}

French abounds with SLEs (Gingras \& Sénéchal, 2017), presenting a substantial challenge for children learning to spell (Sénéchal et al., 2016). However, if the SLE contains morphological information, as morphogrammes do, then children's morphological knowledge may provide recourse, as they can consider derived members of a word family when recalling the root word's ending (Sénéchal, 2000; Fejzo, 2016). While the present study failed to replicate previous findings that morphological knowledge predicts children's morphogramme spelling, it did provide a thorough review of the construct of morphological knowledge, and the instruments used to measure it. Notably, even when measures were assumed to assess either implicit or explicit morphological skills, all measures were found to assess a single, unified factor. Furthermore, the present study explored an avenue for new research into children's overgeneralization of SLEs. Overall, the present study expands upon our understanding of morphological knowledge and SLE spelling in young elementary children, and highlights the 
importance of measurement selection when the construct of interest, such as morphological knowledge, may be unstable in the target population. 


\section{References}

Abbott, R. D., Fayol, M., Zorman, M., Casalis, S., Nagy, W., \& Berninger, V. W. (2016). Relationships of French and English Morphophonemic Orthographies to Word Reading, Spelling, and Reading Comprehension During Early and Middle Childhood. Canadian journal of school psychology, 31(4), 305-321.

Adams, M. (1990). Beginning to read: Thinking and learning about print. Cambridge, MA: MIT Press.

Anderson, S. 1990. A-morphous morphology. MS. Cognitive Science Centre Baltimore: The Johns Hopkins University.

Anglin, J. M., Miller, G. A., \& Wakefield, P. C. (1993). Vocabulary development: A morphological analysis. Monographs of the society for research in child development, i186.

Baumann, J. F., Edwards, E. C., Font, G., Tereshinski, C. a, Kame, E. J., \& Olejnik, S. (2002). Teaching morphemic and contextual analysis to fifth grade students. Reading Research Quarterly, 37(2), 150-176.

Berko, J. (1958). The child's learning of English morphology. Word, 14, 150-177.

Berninger, V., Abbott, R., Nagy, W., \& Carlisle, J. (2009) Growth in Phonological, Orthographic, and Morphological Awareness in Grades 1 to 6. Journal of Psycholinguistic Research, 39, 141-163.

Beyersmann, E., Ziegler, J. C., \& Grainger, J. (2015). Differences in the processing of prefixes and suffixes revealed by a letter-search task. Scientific Studies of Reading, 19(5), 360373. doi:http://dx.doi.org.proxy.library.carleton.ca/10.1080/10888438.2015.1057824

Bosse, M. L., \& Pacton, S. (2006). Comment l'enfant produit-il l'orthographe des mots? 
Bowers, P. N., Kirby, J. R., \& Deacon, S. H. (2010). The effects of morphological instruction on literacy skills: A systematic review of the literature. Review of educational research, 80(2), 144-179.

Campbell, R., \& Sais, E. (1995). Accelerated metalinguistic (phonological) awareness in bilingual children. British Journal of Developmental Psychology, 13(1), 61-68.

Carlisle, J. (2000). Awareness of the structure and meaning of morphologically complex words: Impact on reading. Reading and Writing: An Interdisciplinary Journal, 12, 169-190.

Carlisle, J. F. (2003). Morphology matters in learning to read: A commentary. Reading Psychology, 24, 291-322.

Carlisle, J. F. (2010). Effects of instruction in morphological awareness on literacy achievement: An integrative review. Reading Research Quarterly, 45(4), 464-487. doi: 10.1598/RRQ.45.4.5

Carlisle, J. F., \& Nomanbhoy, D. M. (1993). Phonological and morphological awareness in first graders. Applied psycholinguistics, 14(2), 177-195.

Carroll, J. B., Davies, P., \& Richman, B. (Eds.). (1971). The American Heritage word frequency book. Boston: Houghton Mifflin.

Casalis, S., \& Louis-Alexandre, M. F. (2000). Morphological analysis, phonological analysis and learning to read French: A longitudinal study. Reading and Writing, 12(3), 303-335.

Clark, E. V., \& Hecht, B. F. (1982). Learning to coin agent and instrument nouns. Cognition, $12(1), 1-24$.

Colé, P., Royer, C., Leuwers, C., \& Casalis, S. (2004). Les connaissances morphologiques dérivationnelles et l'apprentissage de la lecture chez l'apprenti-lecteur français du CP au CE2. L'Année psychologique, 104(4), 701-750. 
Cortina, J. M. (1993). What is coefficient alpha? An examination of theory and applications. Journal of Applied Psychology, 78(1), 98-104.

Crammer, S., Gill, J., Jackson, N., Murr, A. \& Armstrong, D. (2016). hot.deck: Multiple HotDeck Imputation. R package version 1.1

Cranmer, S.J. and Gill, J.M.. (2013) "We Have to Be Discrete About This: A Non-Parametric Imputation Technique for Missing Categorical Data.” British Journal of Political Science $43: 2(425-449)$.

Deacon, S. H., Parrila, R., \& Kirby, J. R. (2008). A review of the evidence on morphological processing in dyslexics and poor readers: A strength or weakness. The Sage handbook of dyslexia, 212-237.

Desrochers, A., Manolitsis, G., Gaudreau, P., \& Georgiou, G. (2018). Early contribution of morphological awareness to literacy skills across languages varying in orthographic consistency. Reading and Writing, 1-25.

Fejzo, A. (2016). The contribution of morphological awareness to the spelling of morphemes and morphologically complex words in French. Reading and Writing, 29(2), 207-228.

Gingras, M., \& Sénéchal, M. (2017). Silex: A database for silent-letter endings in French words. Behavior research methods, 49(5), 1894-1904.

Gingras, M., \& Sénéchal, M. (2018). Evidence of Statistical Learning of Orthographic Representations in Grades 1-5: The Case of Silent Letters and Double Consonants in French. Scientific Studies of Reading, 1-12.

Goodwin, A. P., \& Ahn, S. (2010). A meta-analysis of morphological interventions: Effects on literacy achievement of children with literacy difficulties. Annals of Dyslexia, 60(2), 183208. 
Howell, D. (Ed.) (2008). Méthodes statistiques en sciences humaines. Bruxelles: De boeck.

Hurry, J., Nunes, T., Bryant, P., Pretzlik, U., Parker, M., Curno, T., \& Midgley, L. (2005). Transforming research on morphology into teacher practice. Research Papers in Education. 20. DOI: 10.1080/02671520500078291.

Jaffré, J.-P., \& Fayol, M. (2006). Orthography and literacy in french. In R. M. Joshi \& P. G. Aaron (Eds.), Handbook of orthography and literacy (pp. 81-104). Mahwah, New Jersey, London: Lawrence Erlbaum Associates.

Kirby, J. R., Deacon, S. H., Bowers, P. N., Izenberg, L., Wade-Woolley, L., \& Parrila, R. (2012). Children's morphological awareness and reading ability. Reading and Writing, 25(2), $389-410$.

Kruk, R. S., \& Bergman, K. (2013). The reciprocal relations between morphological processes and reading. Journal of Experimental Child Psychology, 114(1), 10-34. doi: 10.1016/j.jecp.2012.09.014

Kuczaj, S. A. (1979). Evidence for a language learning strategy: On the relative ease of acquisition of prefixes and suffixes. Child Development, 1-13.

Kuo, L., \& Anderson, R. C. (2006). Morphological awareness and learning to read: A crosslanguage perspective. Educational Psychologist, 41(3), 161-180. doi: 10.1207/s15326985ep4103_3

Lam, K., \& Chen, X. (2017). The crossover effects of morphological awareness on vocabulary development among children in French immersion. Reading and Writing, 31(8), 1893 1921.

Matsunaga, M. (2015). How to factor-analyze your data right: do’s, don'ts, and how-to’s. International Journal of Psychological Research, 3(1), 97-110. 
Nagy, W. E., Anderson, R. (1984). How many words in printed school English? Reading Research Quarterly, 19, 304-330.

Nagy, W. E., Carlisle, J. F., \& Goodwin, A. P. (2013). Morphological knowledge and literacy acquisition. Journal of Learning Disabilities, 47(1), 3-12.

doi:/10.1177/0022219413509967

Nagy, W., Berninger, V., Abbott, R., Vaughan, K., \& Vermeulen, K. (2003). Relationship of morphology and other language skills to literacy skills in at-risk second-grade readers and at-risk fourth-grade writers. Journal of Educational Psychology, 95(4), 730-742. DOI: $10.1037 / 0022-0663.95 .4 .730$

New, B., Pallier, C., Brysbaert, M., \& Ferrand, L. (2004). Lexique 2: A New French lexical database. Behavior Research Methods, Instruments, \& Computers, 36, 516-524.

Ouellette, G. (2010). Orthographic learning in learning to spell: The roles of semantics and type of practice. Journal of Experimental Child Psychology, 107(1), 50-58.

Peereman, R., Lété, B., \& Sprenger-Charolles, L. (2007). Manulex-infra: Distributional characteristics of grapheme-phoneme mappings, and infralexical and lexical units in child-directed written material. Behavior Research Methods, 39, 593-603.

Québec Ministère de l'Éducation et de l'Enseignement supèrieur. (2009). Progression des apprentissages au primaire Français, langue d'enseignement. Retrieved September 26, 2017 from http://www.education.gouv.qc.ca/fileadmin/site_web/documents/education/jeunes/pfeq/P DA_PFEQ francais-langue-enseignement-primaire_2011.pdf

Quémart, P., \& Casalis, S. (2017). Morphology and spelling in French students with dyslexia: the case of silent final letters. Annals of dyslexia, 67(1), 85-98. 
Sanchez, M., Magnan, A., \& Ecalle, J. (2012). Knowledge about word structure in beginning readers: what specific links are there with word reading and spelling?. European journal of psychology of education, 27(3), 299-317.

Sénéchal, M. (2000). Morphological effects in children's spelling of French words. Canadian Journal of Experimental Psychology/Revue canadienne de psychologie expérimentale, 54(2), 76 .

Sénéchal, M., Basque, M. T., \& Leclaire, T. (2006). Morphological knowledge as revealed in children's spelling accuracy and reports of spelling strategies. Journal of experimental child psychology, 95(4), 231-254.

Sénéchal, M., \& Kearnan, K. (2007). The role of morphology in reading and spelling. In R. V. Kail (Ed.), Advances in child development and behavior (vol. 35); advances in child development and behavior (vol. 35) (pp. 297-325, Chapter xi, 414 Pages) Elsevier Academic Press, San Diego, CA. Retrieved from http://proxy.library.carleton.ca/login?url=https://search-proquestcom.proxy.library.carleton.ca/docview/622194445?accountid=9894

Sénéchal, M., Gingras, M., \& L’Heureux, L. (2016). Modeling spelling acquisition: The effect of orthographic regularities on silent-letter representations. Scientific Studies of Reading, 20, 155-162. doi:10.1080/10888438.2015.1098650

Sénéchal, M., \& Rey, V. (2007). Personal communication.

St. Clair, M. C., Monaghan, P., \& Ramscar, M. (2009). Relationships between language structure and language learning: The suffixing preference and grammatical categorization. Cognitive Science, 33(7), 1317-1329. 
Tavakol, M., \& Dennick, R. (2011). Making sense of Cronbach's alpha. International journal of medical education, 2, 53-55. doi:10.5116/ijme.4dfb.8dfd

Tyler, A., \& Nagy, W. (1989). The acquisition of English derivational morphology. Journal of Memory and Language, 28, 649-667.

Van Heugten, M., \& Shi, R. (2009). French-learning toddlers use gender information on determiners during word recognition. Developmental Science, 12(3), 419-425.

Ziegler, J. C., Jacobs, A. M., \& Stone, G. O. (1996). Statistical analysis of the bidirectional inconsistency of spelling and sound in French. Behavior Research Methods, Instruments, \& Computers, 28(4), 504-515. 


\section{Appendix}

Measures Used in the Present Study

The following are the seven measures used in the present study, along with their instructions (in the original French) and answer keys. 


\section{RELATEDNESS}

Consigne: «Dans ce jeu, je vais te donner 2 mots qui se ressemblent un peu. Tu dois me dire à chaque fois si les mots que je te décris sont de la même famille ou pas. On va s'entraîner un peu: Chat et chaton, est-ce que ces mots sont de la même famille ou pas? » Si l'enfant dit oui, on répond: «Bravo, ces deux mots sont de la même famille. » Si l'enfant dit non, on répond: « Bon effort mais la réponse est oui, chaton vient du mot Chat, alors ils sont de la même famille. Gentil... gentillesse. Pizza-pizzaria.... Chat et châssis, est-ce que ces mots sont de la même famille ou pas? " Si l'enfant dit non, on répond: "Bravo, ces deux mots se ressemblent, mais ils ne sont pas de la même famille." Si l'enfant dit oui, on répond: «Bon effort mais la réponse est non, chat et châssis ne sont pas de la même famille. " Feedback pour les exemples. Aucun feedback pour les mots tests.

Exemples: gentil gentillesse pizza-pizzaria chat-châssis

\begin{tabular}{|l|l|l|ll|}
\hline & Racine & Dérivé & Réponse & \\
\hline 1. & bague & bagage & oui & non \\
\hline 2. & glisser & glissade & oui & non \\
\hline 3. & cour & courage & oui & non \\
\hline 4. & gaz & gazon & oui & non \\
\hline 5. & châle & chaleur & oui & non \\
\hline 6. & heure & heureux & oui & non \\
\hline 7. & grille & grillage & oui & non \\
\hline 8. & ville & village & oui & non \\
\hline 9. & pomme & pommade & oui & non \\
\hline 10. & bagarre & bagarreur & oui & non \\
\hline 11. & chat & château & oui & non \\
\hline 12. & boxe & boxeur & oui & non \\
\hline 13. & sang & sanglier & oui & non \\
\hline 14. & balle & ballon & oui & non \\
\hline 15. & couler & couleur & oui & non \\
\hline 16. & amour & amoureux & oui & non \\
\hline 17. & salade & saladier & oui & non \\
\hline 18. & bercer & berceau & oui & non \\
\hline 19. & cloche & clochette & oui & non \\
\hline 20. & casser & cassette & oui & non \\
\hline & & & & \\
\hline
\end{tabular}




\section{Traditional Decomposition}

Consigne: «Écoute bien les mots dont je vais te dire et dis-moi si tu trouves un plus petit mot à l'intérieur de chacun. Je vais te donner un exemple. Amical. Trouve un plus petit mot à l'intérieur de ce mot. " Si l'enfant dit ami, on répond: «Bravo, ami est un plus petit mot à l'intérieur du mot amical. » Si l'enfant ne dit pas ami, on répond: « Bon effort mais la réponse est ami. Ami est un plus petit mot à l'intérieur du mot amical. » Répètez les mêmes instructions pour les deux autres exemples. Aucun feedback pour les mots tests.

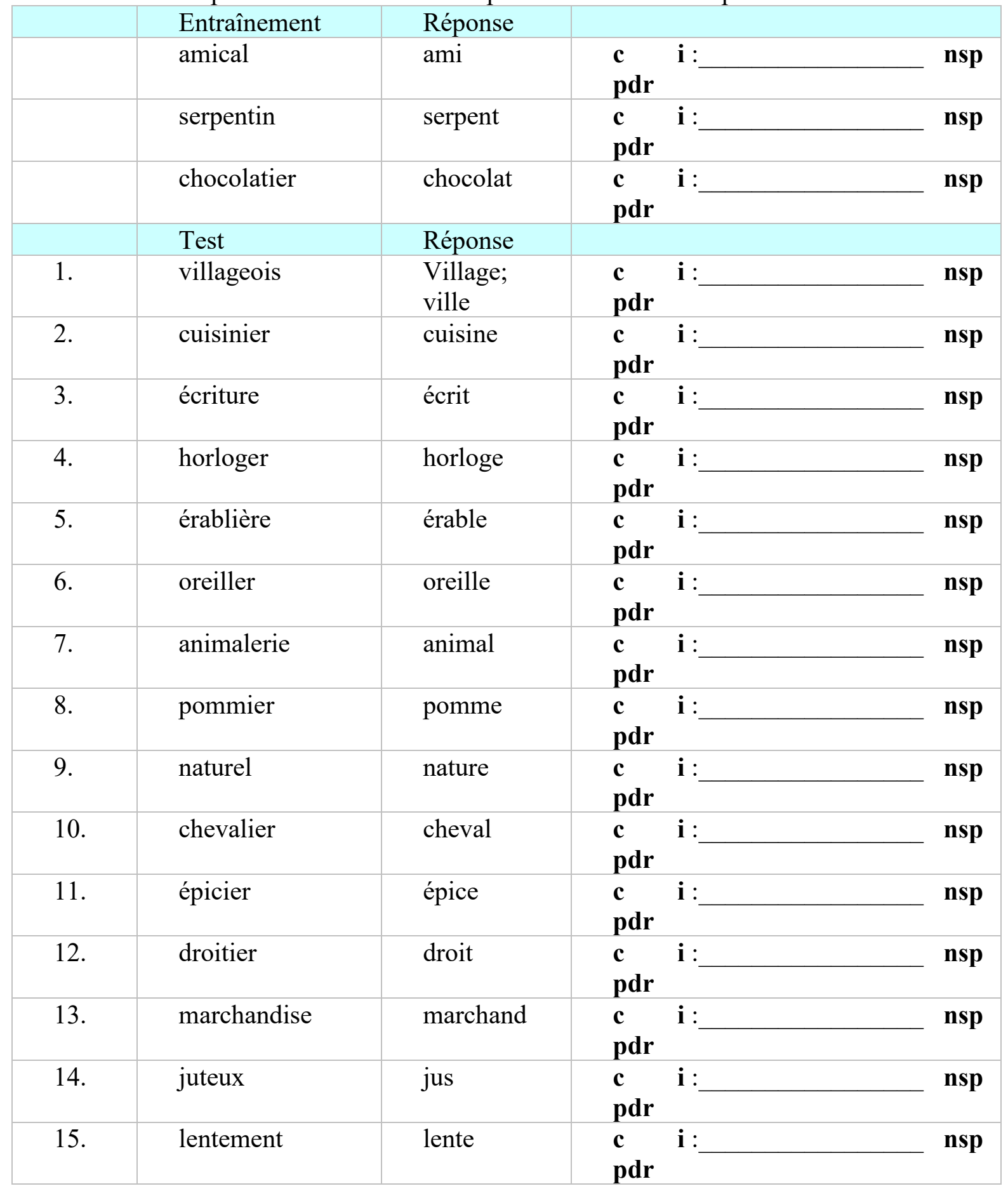




\begin{tabular}{|c|c|c|c|c|}
\hline 16. & bavarder & bavard & $\begin{array}{ll}\text { c } & \mathbf{i}: \\
\text { pdr }\end{array}$ & nsp \\
\hline 17. & lignée & ligne & $\begin{array}{ll}\text { c } & \mathbf{i}: \\
\text { pdr }\end{array}$ & nsp \\
\hline 18. & bouffonnerie & bouffonne & $\begin{array}{ll}\text { c } & \mathbf{i}:\end{array}$ & nsp \\
\hline 19. & porcherie & porc & $\begin{array}{l}\text { c } \quad i: \\
\text { pdr }\end{array}$ & nsp \\
\hline 20. & fabricant & fabrique & $\begin{array}{l}\text { c } \quad i: \\
\text { pdr }\end{array}$ & nsp \\
\hline
\end{tabular}

Note. $\mathrm{C}=$ correct; $\mathrm{i}=$ incorrect; $\mathrm{pdr}=$ pas de réponse $[$ no answer $]$; $\mathrm{nsp}=$ ne sais pas [i don't know] 


\section{Morpho-Phono Decomposition}

Écoute bien ce que je vais te dire. Certains mots contiennent un petit mot, et d'autres mots ne contiennent pas un petit mot. Par exemple, trouve un petit mot dans le mot « dentier ». Si l'enfant dit « dent »; bravo, « dent » est un petit mot à l'intérieur du mot « dentier ». Si l'enfant ne dit pas « dent », bon effort, mais la réponse est « dent». « dent » est un petit mot à l'intérieur du mot « dentier »Dans le mot requin, y-a-t-il un plus petit mot ? Si l'enfant dit non, répond « bravo, il n'y a pas de petit mot à l'intérieur du mot « requin ». Si l'enfant dit « oui », on répond, «bon effort, mais il n'y a pas de petit mot à l'intérieur du mot « requin ».

\begin{tabular}{|c|c|c|c|c|}
\hline Mots & $\begin{array}{l}\text { réponse } \\
\text { phono }\end{array}$ & $\begin{array}{l}\text { réponse } \\
\text { morpho }\end{array}$ & Réponse aucun pt & $\begin{array}{l}\text { correct/incorrect } \\
(1 \text { ou } 0)\end{array}$ \\
\hline 1. Rebond & on & bond & & \\
\hline 2. Café & fée & & $\mathrm{XX}$ & \\
\hline 3. Coquille & quille & coque & & \\
\hline 4. Horrible & Or, riz & & $\mathrm{XX}$ & \\
\hline 5. Debout & Âout & bout & & \\
\hline 6. Tomate & Matte, ma & & $\mathrm{XX}$ & \\
\hline 7. Griffure & Gris & griffe & & \\
\hline 8. Bouteille & Bout & & $\mathrm{XX}$ & \\
\hline 9. Impure & un & pure & & \\
\hline 10. Jurer & jus & & $\mathrm{xX}$ & \\
\hline 11. Fermier & Fer & ferme & & \\
\hline 12. Survol & Sur & vol & & \\
\hline 13. Droitier & roi & droit ,droite & & \\
\hline 14. Cochon & Coche, on & & $\mathrm{XX}$ & \\
\hline 15. Plombier & et & plomb & & \\
\hline 16. Pressoir & soir & presse & & \\
\hline 17. Jouet & Et, joue & & $\mathrm{XX}$ & \\
\hline 18. Caverne & ver & cave & & \\
\hline 19. Pardon & par, don & & $\mathrm{XX}$ & \\
\hline 20. Pelouse & Pelle,loup & & $\mathrm{xX}$ & \\
\hline 21. Bajoue & bas & joue & & \\
\hline 22. Canon & non ,cane, on & & $\mathrm{XX}$ & \\
\hline 23. Achat & Chat,hache & & $\mathrm{xX}$ & \\
\hline 24. Profil & pro, prof, fil & & $\mathrm{Xx}$ & \\
\hline 25. Impropre & un & propre & & \\
\hline 26. Copine & pin & & $\mathrm{XX}$ & \\
\hline 27. Planchette & Plan & planche & & \\
\hline 28. Rebord & or & bord & & \\
\hline 29. Faiblir & Fait,lire & faible & & \\
\hline 30. Départ & dé & part & & \\
\hline
\end{tabular}




\section{Analogy}

Consigne: « Voici un autre jeu de mots. Je vais te dire une paire de deux mots. Écoute bien pour deviner le lien entre les deux mots. Ensuite, je te donne le premier mot d'une autre paire et toi tu dois me dire le mot qui manque. Le mot qui manque a le même lien que la première paire de mots. Je vais te donner un exemple. Chien: chienne. Chien: chienne. Ensuite, je te donne chat. Quel mot manque à chat pour que ce soit pareil à chien: chienne. chat :__. Écoute chien: chienne, chat : . " Feedback pour les exemples. Aucun feedback pour les mots tests.

Exemples :

a. chien: chienne

b. content: contente

c. deux: deuxième

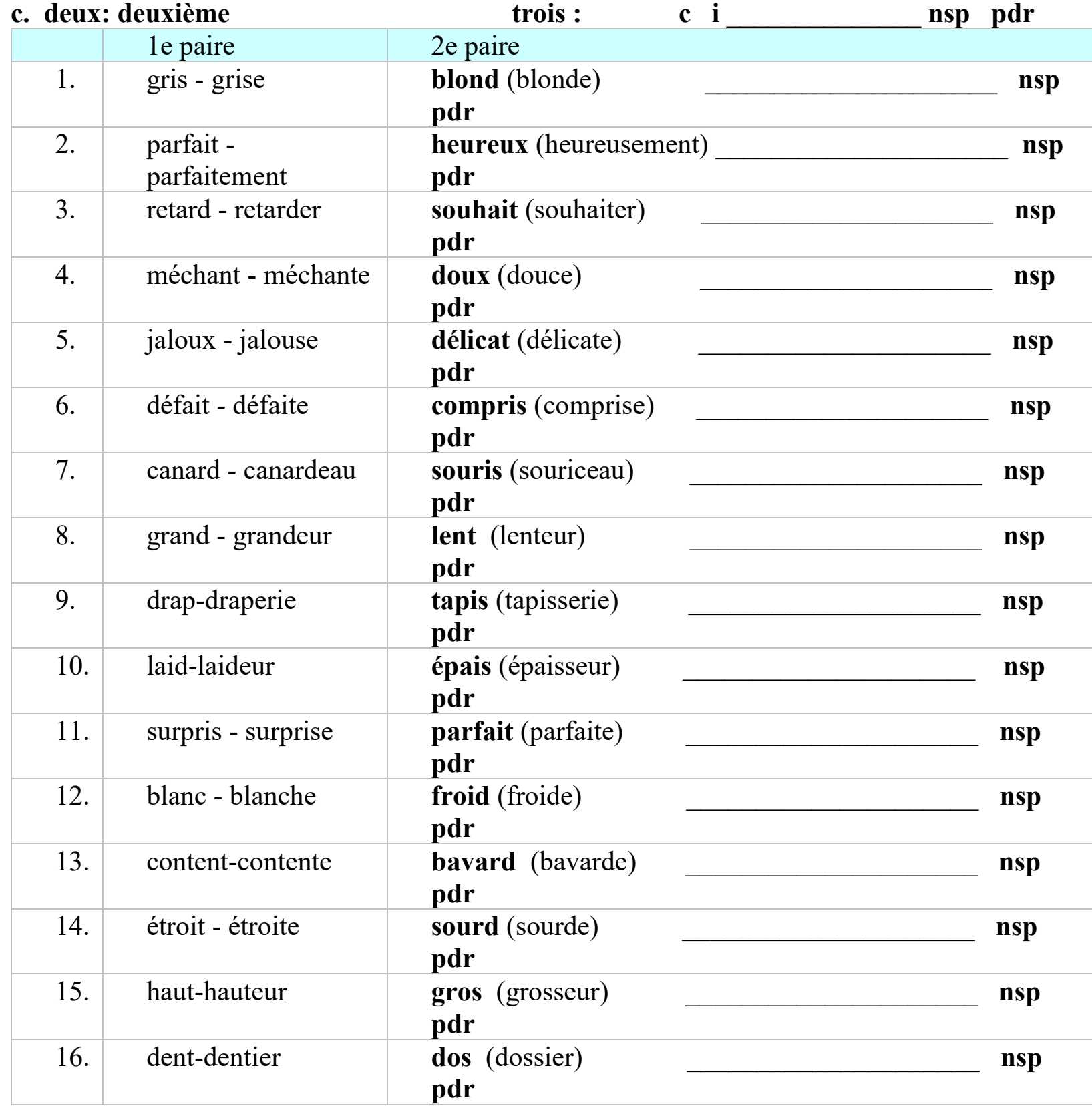




\begin{tabular}{|c|c|c|c|}
\hline 17. & chaud - chaudement & $\begin{array}{l}\text { gratuit (gratuitement) } \\
\text { pdr }\end{array}$ & nsp \\
\hline 18. & regard-regarder & $\begin{array}{l}\text { aliment (alimenter) } \\
\text { pdr }\end{array}$ & nsp \\
\hline 19. & renard - renardeau & $\begin{array}{l}\text { éléphant (élépanteau) } \\
\text { pdr }\end{array}$ & nsp \\
\hline 20. & ment - menteur & $\begin{array}{l}\text { vend (vendeur) } \\
\text { pdr }\end{array}$ & nsp \\
\hline
\end{tabular}

Note. $\mathrm{pdr}=$ pas de response [no answer]; $\mathrm{nsp}=$ ne sais pas [i don't know] 


\section{Morphogramme Spelling}

Tu vas voir 30 séries de trois mots. Les 3 mots dans chacune des séries se prononcent de la même façon. Maintenant, mets ton doigt sur le numéro 1, lis les 3 mots et tu vas choisir celui qui est écrit correctement. Lorsque tu as fait ton choix, tu dois encercler ta réponse. Tu dois encercler une réponse même si tu n'es pas certain. Par la suite, mets ton doigt sur numéro 2 etc...

\begin{tabular}{|c|c|c|c|}
\hline 1. & chocolat & chocolas & chocola \\
\hline 2. & matela & matelas & matelat \\
\hline 3. & tapi & tapis & tapit \\
\hline 4. & retard & retar & retart \\
\hline 5. & ran & rang & rant \\
\hline 6. & combas & combat & comba \\
\hline 7. & biscuit & biscuis & biscui \\
\hline 8. & aimand & aiman & aimant \\
\hline 9. & sabo & sabop & sabot \\
\hline 10. & lézard & lézar & lézart \\
\hline 11. & repo & repot & repos \\
\hline 12. & argumend & argument & argumen \\
\hline 13. & diaman & diamand & diamant \\
\hline 14. & canot & cano & canop \\
\hline 15. & spor & spord & sport \\
\hline 16. & plon & plomb & plont \\
\hline 17. & galot & galo & galop \\
\hline 18. & serpent & serpen & serpend \\
\hline 19. & confort & conford & confor \\
\hline 20. & documen & documend & document \\
\hline 21. & habid & habit & habi \\
\hline 22. & ragoût & ragoûx & ragoû \\
\hline 23. & charios & chario & chariot \\
\hline 24. & transpord & transport & transpor \\
\hline 25. & torren & torrent & torrend \\
\hline 26. & milliard & milliar & milliart \\
\hline 27. & fusit & fusi & fusil \\
\hline 28. & avocat & avocas & avoca \\
\hline 29. & dra & drap & drat \\
\hline 30. & outil & outit & outi \\
\hline
\end{tabular}

Note. The correct answer is bolded. 


\section{General Spelling}

Tu vas voir des séries de 2 mots. Les 2 mots dans chacune des séries se prononcent de la même façon. Mets ton doigt sur le numéro 1, lit les deux mots et tu vas choisir celui qui est écrit correctement. Lorsque tu as fait ton choix, tu dois encercler ta réponse. Tu dois encercler un des deux mots même si tu n'es pas certain. Par la suite, mets ton doigt sur le numéro 2 etc.

\begin{tabular}{|c|c|c|}
\hline 1. & graisse & graice \\
\hline 2. & orteille & orteil \\
\hline 3. & bombon & bonbon \\
\hline 4. & quille & qille \\
\hline 5. & garder & guarder \\
\hline 6. & tanbour & tambour \\
\hline 7. & frein & frain \\
\hline 8. & guarderie & garderie \\
\hline 9. & naige & neige \\
\hline 10. & frapper & fraper \\
\hline 11. & jambe & jembe \\
\hline 12. & fain & faim \\
\hline 13. & sauce & sausse \\
\hline 14. & cinture & ceinture \\
\hline 15. & menton & manton \\
\hline 16. & sommeille & sommeil \\
\hline 17. & guardienne & gardienne \\
\hline 18. & magasin & magazin \\
\hline 19. & trésor & trézor \\
\hline 20 . & rappel & rapel \\
\hline 21. & baucal & bocal \\
\hline 22. & painture & peinture \\
\hline 23. & jirafe & girafe \\
\hline 24. & brosse & broce \\
\hline 25. & baleine & balaine \\
\hline 26. & flaucon & flocon \\
\hline 27. & japper & japer \\
\hline 28. & trein & train \\
\hline 29. & bule & bulle \\
\hline 30. & reine & raine \\
\hline
\end{tabular}

Note. The correct answer is bolded. 


\section{Phonological Decoding}

Tu vas voir 30 paires de mots qui sont écrits bizarrement. Lis les deux mots et choisi celui qui se prononce comme un vrai mot. Lorsque tu as fait ton choix, tu dois encercler ta réponse. Tu dois encercler un des deux mots même si tu n'es pas certain.

\begin{tabular}{|c|c|c|}
\hline 1. & fraze & traze \\
\hline 2. & phrès & drès \\
\hline 3. & harfé & harmé \\
\hline 4. & kuillaire & tuillaire \\
\hline 5. & réamp & jéamp \\
\hline 6. & liot & liom \\
\hline 7. & rekin & tekin \\
\hline 8. & éguiye & éguipe \\
\hline 9. & sate & saje \\
\hline 10. & movet & mopet \\
\hline 11. & umin & ubin \\
\hline 12. & amphant & amdant \\
\hline 13. & loce & lèce \\
\hline 14. & geois & geoif \\
\hline 15. & aksidont & aksidant \\
\hline 16. & mahibe & mahisse \\
\hline 17. & fainke & sainke \\
\hline 18. & rèzon & rèton \\
\hline 19. & mévrié & phévrié \\
\hline 20 . & seinje & feinje \\
\hline 21. & geamès & geomès \\
\hline 22. & daremps & paremps \\
\hline 23. & hinoscent & binoscent \\
\hline 24. & genvié & genrié \\
\hline 25 . & cefrait & cekrait \\
\hline 26. & açanfeur & açanceur \\
\hline 27. & geardaim & gearlaim \\
\hline 28. & rèzim & rèmin \\
\hline 29. & muque & duque \\
\hline 30. & katé & karé \\
\hline
\end{tabular}

Note. The correct answer is bolded. 


\section{Pseudoword Spelling (Overgeneralization of SLEs)}

Consigne: « Maintenant, vous allez écrire sur cette page les mots dont je vais vous dicter. Les mots que vous allez écrire ne sont pas des vrais mots, nous les avons inventés. Je vais d'abord vous dire le numéro d'une ligne et ensuite je vais lire le mot deux fois que vous aurez à écrire sur cette ligne. Vous allez voir que la première partie du mot est déjà écrite pour vous. Vous n'avez qu'à compléter le mot. Essayez d'écrire tous les mots même si vous n'êtes pas sûres de l'orthographe. Allez à la ligne 1 sur votre page. Écoutez attentivement. Numéro 1. juti, juti. »

Ordre des items de la dictée:

1. juti

2. fenar

3. pada

4. falo

5. ranan

6. cajor

7. rajo

8. bivar

9. mouco

10. ciror

11. moufa

12. bonan

13. juna

14. cabi

15. ravor

16. cinan

17. mofi

18. dassar 